\title{
PhiMiSci
}

Philosophy and the Mind Sciences

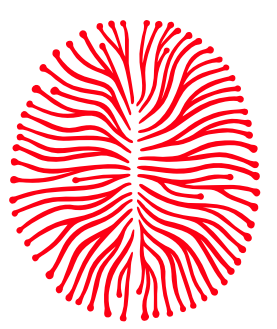

\section{The varieties of selflessness}

\author{
Raphaël Millière $^{\mathrm{a}}$ (D) (raphael.milliere@philosophy.ox.ac.uk)
}

\begin{abstract}
Many authors argue that conscious experience involves a sense of self or self-consciousness. According to the strongest version of this claim, there can be no selfless states of consciousness, namely states of consciousness that lack self-consciousness altogether. Disagreements about this claim are likely to remain merely verbal as long as the target notion of self-consciousness is not adequately specified. After distinguishing six notions of self-consciousness commonly discussed in the literature, I argue that none of the corresponding features is necessary for consciousness, because there are states of consciousness in which each of them is plausibly missing. Such states can be said to be at least partially selfless, since they lack at least one of the ways in which one could be self-conscious. Furthermore, I argue that there is also preliminary empirical evidence that some states of consciousness lack all of these six putative forms of self-consciousness. Such states might be totally selfless, insofar as they lack all the ways in which one could be self-conscious. I conclude by addressing four objections to the possibility and reportability of totally selfless states of consciousness.
\end{abstract}

\section{Keywords}

Dreamless sleep · Drug-induced states - Global states of consciousness · Meditation · Psychopathology $\cdot$ Self-consciousness $\cdot$ Selflessness

This article is part of a special issue on "Radical disruptions of self-consciousness", edited by Thomas Metzinger and Raphaël Millière.

\section{Introduction}

Many authors in philosophy, psychology and neuroscience are sympathetic to the claim that conscious experience involves a sense of self. In first approximation, a subject's overall experience involves a sense of self at $t$ if and only if (a) the subject is self-conscious at $t$, and (b) the subject's being self-conscious at $t$ makes a constitutive contribution to her overall phenomenology at $t .^{1}$

${ }^{a}$ University of Oxford

${ }^{1}$ While the clause (b) may seem somewhat redundant, it is intended to highlight the fact that the notion of "sense of self" or "self-consciousness" under consideration is a phenomenal one - rather 
The claim that conscious experience involves a sense of self comes in two varieties, depending on the alleged prevalence of the target phenomenon. According to the Necessity Claim (NC), self-consciousness is necessary for consciousness in general. ${ }^{2}$ According to the Typicality Claim (TC), self-consciousness is merely pervasive in ordinary experience. ${ }^{3}$

These two claims can be formulated more precisely as follows:

NC For any subject $S$, if $S$ is conscious at $t$, then (a) $S$ is self-conscious at $t$, and (b) $S$ 's being self-conscious at $t$ makes a constitutive contribution to $S$ 's overall phenomenology at $t$.

TC For any healthy, neurotypical, adult human subject $S$, in any ordinary condition in which $S$ is conscious, (a) $S$ is self-conscious, and (b) $S$ 's being selfconscious in that condition makes a constitutive contribution to $S$ 's overall phenomenology. ${ }^{4}$

In this article, I focus mostly on the strongest of these claims: NC. Proponents of NC deny that there can be selfless states of consciousness, namely states of consciousness that lack self-consciousness entirely. In section 2 , I suggest that disagreements about the prevalence of self-consciousness in conscious experience are difficult to arbitrate unless the target notion of self-consciousness is adequately specified. Accordingly, I distinguish six notions of self-consciousness commonly

than a dispositional notion such as the capacity to use a concept of self. The inclusion of the qualifier "constitutive" is intended to highlight the fact that the relevant contribution to the subject's phenomenology is not merely causal, since a non-conscious mental state could indirectly cause a change in a subject's phenomenology (e.g. a non-conscious desire for ice cream could cause a subject to feel hungry, thereby indirectly causing a change in the subject's phenomenology).

${ }^{2}$ For example: "If 'self-consciousness' is taken to mean 'consciousness with a sense of self', then all human consciousness is necessarily covered by the term - there is just no other kind of consciousness as far as I can see" (Damasio, 1999, p. 19); "If a mental state is conscious, that mental state will involve a non-reflective self-awareness" (Gallagher, 2010, p. 567); "self-consciousness is a constitutive feature of phenomenal consciousness" (Zahavi, 2014, p. 17); "[S]elf-awareness is an integral function of all conscious experiences" (Lou, Changeux, \& Rosenstand, 2017, p. 767); "I believe that the self always shows up in every human experience" (Duncan, 2019); "Is self-consciousness necessary for consciousness? The answer is yes." (Friston, 2018, p. 1).

${ }^{3}$ For example: "[Phenomenally] conscious states often seem to have a 'me-ishness' about them; the phenomenal content often represents the state as a 'state of me" " (Block, 1995, p. 235); "There is an elusive sense of self-presence or self-manifestation inherent in even a simple conscious experience of the blue sky. It is less clear to me, however, that this feature [...] is constitutive of phenomenology" (Kriegel, 2009, p. 177); "Self-experience [is] fundamental to the daily experience of all normal human beings [...]. It's a particular way of experiencing oneself that comes to every normal human being in early childhood" (Strawson, 2011, p. 8); "normal experience displays [...] me-ness [i.e., a phenomenal awareness of oneself]" (Guillot, 2017, p. 46).

${ }^{4}$ I purposefully leave open the specific meanings of "healthy", "neurotypical" and "ordinary condition", since different proponents of TC might have slightly different views about these constraints. In general, the claim is intended to apply broadly to conscious experiences occurring in the sober wakeful state, for adult individuals who do not suffer from psychopathologies or neuropathologies.

Millière, R. (2020). The varieties of selflessness. Philosophy and the Mind Sciences, 1(I), 8. 
discussed in the literature; each of these notions, as well as every possible combination of these notions, yields a distinct version of NC that can be assessed more precisely than the generic formulation of the claim. In section 3, I argue that none of these six putative forms of self-consciousness is necessary for consciousness in general, because there are cases in which each of them is plausibly missing. Finally, in section 4, I discuss further evidence that some states of consciousness lack any form of self-consciousness - including evidence about drug-induced states that has remained largely overlooked - thus undermining all versions of NC. I conclude by discussing four objections to the possibility and reportability of totally selfless states of consciousness.

\section{Getting clearer on self-consciousness}

As claims about phenomenology, both NC and TC should in principle be supported by introspection. ${ }^{5}$ Indeed, proponents of these claims often rely on introspective judgements (as evidenced by some of the quotes provided in thnotes 2 and 3). To some, it is simply manifest that conscious experience involves selfconsciousness. Nonetheless, many proponents of those claims cautiously emphasize the elusiveness of the target phenomenon. Thus, the relevant notion of the sense of self is deemed "deep and intangible" (Chalmers, 1996, p. 10), "implicit" (Gallagher \& Zahavi, 2019) or "elusive" (Kriegel, 2009, p. 177). Moreover, there has been no shortage of skepticism regarding the introspective accuracy of NC and TC since Hume's infamous denial that anything like a sense of self can be found in experience. ${ }^{6}$

Introspective disagreements are famously difficult to arbitrate, as they often lead to seemingly intractable disputes in which it is hard for both camps to find common ground. Given the polysemy of the notions of "sense of self" and "selfconsciousness", it is not implausible that disagreements about NC and TC might hinge, at least in part, on terminological variation (Bayne \& Spener, 2010). Indeed, the two sides of the disagreements might lack a common understanding of what they are supposed to notice in their experience, although they could perhaps come to an agreement if the target feature were specified in more detail. Consider, for example, Prinz's skeptical stance on the possibility of experiencing the self in isolation:

Among the various phenomenal qualities that make up an experience, there is none that can be characterized as an experience of the self $[\ldots]$.

\footnotetext{
${ }^{5}$ This does mean, of course, that such claims can be vindicated by introspection alone. As a necessity claim, NC cannot be conclusively defended on the sole basis of reports about phenomenology. However, both NC and TC should be at least consistent with introspection, and it should only take one convincing counter-example to invalidate either claim.

${ }^{6}$ Hume, A Treatise of Human Nature, Book 1, Section 6. There is, of course, some disagreement on the meaning of Hume's comments on the self (see below for neo-Humean positions).
} 
There is no phenomenal I. If I wait for myself to appear in experience, I will never arrive. ${ }^{7}$ (Prinz, 2012, pp. 214-240)

On this neo-Humean view, it is impossible to find a distinctive experience of the self among the various phenomenal qualities that show up in one's stream of consciousness. In other words, there is no such thing as a sui generis qualitative property of selfhood that can be noticed in every conscious experience.

As it turns out, there is a rather widespread agreement that this view is phenomenologically plausible. ${ }^{8}$ In fact, most proponents of NC and TC would agree that the sense of self they deem pervasive in most or all conscious experiences is not "a detachable self quale that one could introspect in isolation from any other content of consciousness" (Zahavi \& Kriegel, 2016, p. 38). In other words, they would happily endorse the claim that all or most conscious states are "selfless" insofar as they lack this feature, although they would maintain that all or most conscious experiences involve self-consciousness in some other sense.

Thus, disagreements about the existence and prevalence of the sense of self in experience are likely to remain merely verbal as long as both sides fail to reach an agreement on the nature of the target phenomenon. One might hope that once NC and TC have been properly disambiguated, the resulting claims can be assessed on their own merit and the disagreement can be ultimately resolved. But what might self-consciousness be, if not a sui generis qualitative property of selfhood?

Self-consciousness is traditionally defined as consciousness of oneself as oneself (Smith, 2017). ${ }^{9}$ This definition is intended to rule out cases in which one might accidentally be conscious of what happens to be oneself, such as when one catches a glimpse of oneself in the mirror but fails to recognize oneself (Kaplan, 1989; Perry, 1979). In other words, genuine self-consciousness has first-personal (de se) content,

\footnotetext{
${ }^{7}$ See Howell (2006) and Dainton (2008) for similar considerations.

${ }^{8}$ Explicit denials of this interpretation of the Humean view are rare, although there are some exceptions such as the following passage quoted by Nathan (1997) (seemingly to endorse it): "I consider [...] my consciousness and feeling of myself, that taste of myself, [to be] more distinctive than the taste of ale or alum, more distinctive than the smell of walnut-leaf or camphor" (Hopkins, 1959, p. 123). See also Duncan (2019): "I experience myself from the inside, so to speak, in roughly the same way that I experience my pains, thoughts, or emotions. The self is among those items that I can be aware of through introspection." (I shall come back to the question of whether there is a ubiquitous qualitative property of selfhood in experience in subsection 4.4.)

${ }^{9}$ There is a long-standing disagreement about whether self-consciousness need be consciousness of oneself, if this is intended to imply a commitment to a realist view of the self. To the extent that instances of self-consciousness have correctness conditions, it might be the case that no such experience is veridical. For example, instances of self-consciousness might systematically misrepresent some existing entity as the self, by analogy with perceptual illusions (McClelland, 2019); or represent a wholly non-existent entity as the self, by analogy with perceptual hallucinations (Bayne, 2010; Metzinger, 2003). In other words, "self-consciousness" need not be a success term. Strictly speaking, then, one would have to define self-consciousness as consciousness of something as oneself (or simply consciousness as of oneself) to remain neutral on this debate. In what follows, I will keep glossing self-consciousness as consciousness of oneself (as oneself) for convenience, although I will assume a neutral stance on the metaphysics of selfhood.
} 
in so far as it is non-accidentally about oneself. In addition, the notion of selfconsciousness is broadly intended to include cases in which one is conscious of a property or part of oneself as one's own. ${ }^{10}$

The general notion of consciousness of oneself as oneself (or consciousness of a property/part of oneself as one's own) is a determinable of more determinate notions. There are a number of candidates in the literature that can arguably be boiled down to six main determinate notions: ${ }^{11}$

1. Cognitive self-consciousness: thinking of oneself as oneself (GarcíaCarpintero, 2015; Guillot, 2016)

2. Spatial self-consciousness: being conscious of one's location (with respect to one's perceived environment) as one's own (Bermudez, 1998; Schwenkler, 2014)

3. Sense of bodily ownership: being conscious of one's body as one's own (de Vignemont, 2018; Martin, 1995)

4. Sense of bodily agency: being conscious of one's bodily actions as one's own (Bayne, 2008; Haggard, 2017)

5. Sense of mental ownership: being conscious of one's mental states as one's own (Billon, 2017b; Zahavi, 2005)

6. Sense of mental agency: being conscious of one's mental actions as one's own (Peacocke, 2006; Proust, 2009)

Each of these determinate notions can be used to formulate distinct versions of NC and TC where they refer to the target feature whose pervasiveness in conscious experience is at issue. For example, the six notions yield the following six versions of NC:

$\mathbf{N C}_{\mathbf{1}}$ For any subject $S$, if $S$ is conscious at $t$, then $S$ 's phenomenology involves cognitive self-consciousness at $t$.

$\mathbf{N C}_{2}$ For any subject $S$, if $S$ is conscious at $t$, then $S$ 's phenomenology involves spatial self-consciousness at $t$.

$\mathbf{N C}_{3}$ For any subject $S$, if $S$ is conscious at $t$, then $S$ 's phenomenology involves $a$ sense of bodily ownership at $t$.

$\mathrm{NC}_{4}$ For any subject $S$, if $S$ is conscious at $t$, then $S$ 's phenomenology involves $a$ sense of bodily agency at $t$.

\footnotetext{
${ }^{10}$ See Chisholm (1969, p. 21).

${ }^{11}$ While I will focus on these six notions in this article, I will consider in subsection 4.4 whether additional notions of self-consciousness could be defined and whether doing so would threaten my overall argument.
} 
$\mathrm{NC}_{5}$ For any subject $S$, if $S$ is conscious at $t$, then $S$ 's phenomenology involves $a$ sense of mental ownership at $t$.

$\mathbf{N C}_{6}$ For any subject $S$, if $S$ is conscious at $t$, then $S$ 's phenomenology involves $a$ sense of mental agency at $t$.

Moreover, insofar as all of these phenomenal features are taken to be determinates of which self-consciousness is a determinable, they can be combined within disjunctive claims that are also versions of NC and TC. Thus, one might claim that the ordinary experience of healthy, neurotypical adults involves cognitive self-consciousness or spatial self-consciousness; and similarly for any other disjunction including two or more of the six phenomenal features listed above. ${ }^{12}$ In particular, there are maximally disjunctive versions of NC and TC, such as:

$\mathbf{N C}_{\text {disj }}$ For any subject $S$, if $S$ is conscious at $t$, then $S$ 's phenomenology involves any of the phenomenal features (1-6) at $t$ (including any combination of these features).

Presumably, the claims resulting from the distinction of determinate notions of self-consciousness are less likely to generate verbal disputes than the generic formulations of NC and TC, because they leave less room for equivocation about the nature of the target phenomenon. Nonetheless, there is plenty of genuine disagreements on whether each of the phenomenal features (1-6) actually exists. It is worth dwelling briefly on the nature of such disagreements. It is fairly uncontroversial that we can entertain thoughts about ourselves, and judge that our spatial location, body, action or mental state is our own. But this does not entail that there is a distinctive experience of thinking about oneself as oneself, or of being aware of one's location, body, action or mental state as one's own. If the six features distinguished above are real and distinct forms of self-consciousness, they ought to come with their own phenomenology and be irreducible to one another. For example, if there is such a thing as a phenomenology of bodily ownership, it should not simply be a matter of thinking of one's body as one's own (de Vignemont, 2018); likewise, if there is a phenomenology of bodily agency, it should not merely be a matter of thinking of one's bodily actions as one's own (Bayne, 2008); and so on for all other relevant features.

In what follows, I shall remain agnostic on the issue of whether any of the phenomenal features (1-6) are ever instantiated in conscious experience. Instead, I will consider whether there is any compelling evidence that they are missing in at least some states of consciousness - independently of whether or not these states occur in the ordinary experience of healthy, neurotypical adults. Thus, my focus will be on the empirical plausibility of various versions of $\mathbf{N C}$. Against $\mathbf{N C}_{\mathbf{1}}-\mathbf{N C}_{\mathbf{6}}$, I will

\footnotetext{
${ }^{12}$ If we limit the analysis to these six determinate notions, this yields a total of $64\left(2^{6}\right)$ possible
} versions of NC and TC. 
argue that it is possible to find states of consciousness lacking each of the six putative forms of self-consciousness individually. Such states of consciousness are at least partially selfless, insofar as they lack at least some form of self-consciousness. I will then argue that some states of consciousness lack all six putative forms of self-consciousness. Such totally selfless states of consciousness should count as evidence against all versions of $\mathbf{N C}$, including $\mathbf{N C}_{\mathbf{d i s j}}$.

\section{Partial selflessness}

Let us define a partially selfless state of consciousness as a state that lacks at least one form of self-consciousness, but not all:

PSL A global state of consciousness of a subject $S$ is partially selfless if and only if, while being in that state, $S$ is not self-conscious in at least one of the ways in which $S$ can be self-conscious, but does not lack all of the ways in which $S$ can be self-conscious at the same time.

By contrast, let us define a totally selfless state of consciousness as a state that lacks all forms of self-consciousness:

TSL A global state of consciousness of a subject $S$ is totally selfless if and only if, while being in that state, $S$ is not self-conscious in any way in which $S$ can be self-conscious (if $S$ can be self-conscious at all).

If none of the putative forms of self-consciousness (1-6) exist, and no other form of self-consciousness exists, it trivially follows that all states of consciousness are totally selfless. If only one of the putative forms of self-consciousness (1-6) exists, then any state of consciousness lacking this unique form of self-consciousness will be totally selfless. Finally, if several of the putative forms of self-consciousness (1-6) exist, then there might be different types of partially selfless states that differ with respect to the form(s) of self-consciousness they are lacking. States of consciousness that credibly lack one of the putative forms of self-consciousness distinguished in the previous section should be considered to be at least partially selfless, while states of consciousness that lack all of them should be considered to be totally selfless.

\subsection{Consciousness without cognitive self-consciousness}

The question of whether there can be states of consciousness in which one does not consciously think of oneself as oneself is rather straightforward. ${ }^{13}$ Indeed, it

\footnotetext{
${ }^{13}$ One some versions of the Higher-Order Thought (HOT) theory of consciousness, being in a conscious mental state M necessarily involves thinking that one is in M (Rosenthal, 1986). However, HOT theories are not committed to the claim that higher-order thoughts about first-order mental states should themselves be conscious thoughts. In fact, proponents of the theory readily acknowledge that "the HOTs are typically not conscious thoughts" (Rosenthal, 1997, p. 745).
} 
would be odd to claim that subjects are perpetually thinking of themselves as themselves whenever they are conscious at all. Even the most narcissistic individuals presumably live through some conscious episodes in which they are not thinking about themselves.

Admittedly, we are often lost in thoughts about ourselves, such as the planning and anticipation of future personal goals (see D'Argembeau, 2018, for a review). However, we clearly have a great many thoughts that are not about ourselves in any way. For example, try solving the following equation:

$$
x^{2}+5=13-4
$$

Once you have determined the value of $x$, ask yourself whether you were thinking about yourself in any way while you were pondering the problem. I predict that for you and other readers the answer will be unanimously negative.

In addition to the routine occurrence of thoughts that are not focused on oneself in ordinary experience, there are also global states of consciousness in which self-related thoughts appear to be inhibited, if not suppressed altogether. For example, it has been argued that the performance of attention-demanding activities can induce a state of flow, especially at expert level, characterized by extreme and undivided focus on the task at hand (Csikszentmihalyi, 1990). The Flow State Scale (FSS) was designed to measure different aspects of flow states across nine factors (Jackson \& Marsh, 1996). In a sample of 747 respondents from a variety of competitive and noncompetitive sport activities, the mean score (on a five-point Likert scale) for the FSS factors Concentration on the task at hand (including the item "My attention was focused entirely on what I was doing") and Loss of self-consciousness (including the item "I was not concerned with what others may have been thinking of me") were 3.73 and 3.92 respectively (Jackson \& Eklund, 2004). Similar results were obtained with a sample of 236 music student performing for an examination, with mean scores of 3.53 and 3.12 for the same FSS factors (Wrigley \& Emmerson, 2011). These data suggest that skilled individuals focused on a demanding performance may reach a state in which they are entirely focused on task-related goals, and therefore are unlikely to have thoughts about themselves (as themselves). ${ }^{14}$

Another condition in which cognitive self-consciousness might temporarily subside is meditation. Many meditative practices, especially in the Buddhist tradition, explicitly aim at the cessation of spontaneous thoughts and the focus of attention on sensory stimuli (Fox \& Cahn, forthcoming). Specifically, these practices cultivate meta-awareness of episodes of mind-wandering, by monitoring spontaneous thoughts in order to disengage from them and re-focus attention on a particular object (such as the breath or a mantra) or on a wider awareness of the

\footnotetext{
${ }^{14}$ See Høffding \& Montero (2019), however, for a different perspective on flow states, according to which "the enactment of expertise requires conscious thought" and "one never disappears, as one is always there, exclusively occupied with the momentary task at hand" (p. 17). Note that the authors do mention the possibility that conscious thoughts only emerge when something goes wrong during the task. (I am grateful to Dan Zahavi for bringing this article to my attention.)
} 
present moment (Hasenkamp, 2018). There is some evidence that once attention has been stabilized and the mind "quieted", meditators can undergo conscious episodes entirely lacking in self-referential thoughts (Millière, Carhart-Harris, Roseman, Trautwein, \& Berkovich-Ohana, 2018).

Finally, it is plausible that the experience of dreaming is often free of cognitive self-consciousness. An analysis of 500 rapid eye movement (REM) dreams found that only $20 \%$ of dream reports included instances of thinking, and that such instances made up only $5 \%$ of the content of reported dreams (Meier, 1993). These findings suggest that "different forms of thinking can be lacking in dreams" (Windt, 2015a, p. 424), including thinking of oneself as oneself.

\subsection{Consciousness without spatial self-consciousness}

In section 2, I defined spatial self-consciousness as the subject's consciousness of her location with respect to her perceived environment as her own location. Some perceptual experiences - visual and auditory experiences in particular - represent spatial properties of perceived objects within an egocentric frame of reference (Evans, 1982; Klatzky, 1998). Indeed, such experiences represent the location of environmental landmarks (i.e., objects, properties and events perceived in the subject's environment) with respect to a point of origin, roughly centered on the subject's head in the case of visual and auditory perception. For example, a particular object might be represented as being located on the right hand side at a certain distance from the point of origin of the subject's visuospatial perspective (over there to the right of here). Correlatively, the location of the point of origin of one's visuospatial perspective is itself represented relatively to environmental landmarks. To give a simple example, if an object perceived in the subject's environment is represented as being located at some distance to the right of the subject's point of origin, then it seems that the subject's point of origin will itself be represented as being located at some distance to the left of the relevant object.

A number of authors have gone further in suggesting that in ordinary perceptual experience, the location of the point of origin of a subject's visuospatial perspective with respect to her perceived environment is represented as as the subject's own location (Bermudez, 1998; Bermúdez, 2001; Cassam, 1997; Hurley, 1998; Noë, 2005; Schwenkler, 2014). In other words, environmental landmarks are not simply perceived as located with respect to here, where here refers to the location of the point of origin of the relevant frame of reference (e.g., the visuospatial perspective); they are perceived as located with respect to $m e$, where me refers to the subject as such. As Cassam puts it, "in experiencing objects as spatially related to one, one literally experiences the bodily self as located in the perceived world" (Cassam, 1997, p. 53). Let us call an experience that represents the relative location of the point of origin of its spatial frame of reference as the subject's own location a self-locating experience, and the relevant kind of spatial self-representation selflocating content. Insofar as self-locating content contributes to the phenomenal 
character of self-locating experiences, the latter can be said to constitute instances of self-consciousness - namely, instances of spatial self-consciousness.

Whether ordinary visual and auditory experiences always involve spatial selfconsciousness is a matter of controversy. Since my focus here is on $\mathbf{N C}_{2}$ rather than on the corresponding version of TC, I shall leave aside ordinary visual and auditory experiences, and ask whether there is compelling empirical evidence that some (non-ordinary) states of consciousness lack spatial self-consciousness.

A good starting point for finding evidence is to consider states of consciousness in which stimuli providing information about distant environmental landmarks are not available. This is the case when subjects are deprived of distal sensory modalities such as sight and audition, a condition known as sensory deprivation or perceptual isolation. One of the most effective ways of artificially cutting off distal perception in healthy subjects is the use of so-called flotation tanks (Feinstein et al., 2018). Flotation tanks contain a solution of water and Epsom salts at skin temperature allowing the patient to float supine in darkness and silence. In such conditions, visual, auditory, tactile, proprioceptive, thermal and vestibular signals are extremely attenuated. It is plausible that individuals floating in a such a tank may undergo episodes in which they cannot perceive any environmental landmark. Indeed, even the tactile stimulation coming from the contact with water is extremely attenuated by the lack of movement and the fact that the water is at skin temperature. Thus, flotation tanks and similar sensory deprivation devices should yield, at least occasionally, experiences that lack self-locating content. Although there is little evidence on the phenomenology of experiences induced by flotation tanks from controlled studies, the few qualitative reports available are consistent with this hypothesis:

I [...] just flew away into nothing [...] and could not feel whether I was in the tank or where I was.

(Kjellgren, Buhrkall, \& Norlander, 2010, p. 1252)

[T] here was only me and I was lying there shut in somewhere and I did not know where I was or time or space [...].

(Kjellgren, Lyden, \& Norlander, 2008, p. 644)

I feel like I am losing time and space. (Kjellgren et al., 2008, p. 646)

The extent to which artificial sensory deprivation can completely remove spatial cues about one's position with respect to one's environment is debatable, because the subjects' distal perceptual capacities are not directly impaired. By contrast, some individuals lack distal sensory modalities altogether as a result of genetic conditions, illness or accidental organ damage. For example, the genetic disorder known as Usher syndrome can lead to deafblindness, the combination of hearing and vision loss (Dammeyer, 2014). There is some evidence that individuals with deafblindness can have experiences lacking self-locating content, especially when tactile and vestibular stimuli are attenuated as in flotation tanks. Thus, a deafblind subject with Usher syndrome interviewed about her daily experience described 
commonly recurring episodes in which she appears to completely lose awareness of her spatial location while taking a bath:

Doing nothing but relaxing in the bath I always found I became lost as in relation to where I was... It is a feeling of being there but not there... You are here but not here. You are just existing... [I]f only for a short time I do lose the spatial awareness of the bath... [S]lowly the whole world vanishes... I have no sense of being present in any environment, the disconnect from all is like unplugging from the world... It is like being in a void, a nothingness that is just outside our reality, and I slip into the void when I have a bath... Your sense of where you are... just disappear[s] to nothingness, the world becomes nothing [...]. It is as if the subconscious decides that location is now not needed and turns off the GPS area of the mind. (Millière, 2019, p. 266)

If there is such a thing as experiencing one's location in egocentric space as one's own, it is plausible that such an experience cannot occur when sight and audition are altogether missing and other sensory modalities are strongly attenuated. While anecdotal reports from single subjects should be interpreted with caution, the above report supports this idea.

Aside from sensory deprivation and deafblindness, there is some evidence that expert meditators can undergo states of consciousness described in terms that strongly suggest they lack self-locating content. Thus, a recent study reported that a subject with around 20,000 hours of meditation practice could reliably induce an experience described in the following terms:

I don't have any kind of sense of location [...]. I have no idea where I am [...]. I'm not there basically, just world, so there's no real location. (Ataria, Dor-Ziderman, \& Berkovich-Ohana, 2015 sup. material)

Another study of long-term mindfulness meditation practitioners found that some of them were able to induce a state of "spacelessness" (Berkovich-Ohana, DorZiderman, Glicksohn, \& Goldstein, 2013), described in such terms as "I felt outside time and space" (p. 4) and "the center of space became endless, without a reference point in the middle" (p. 5).

The evidence that meditation can induce states of consciousness lacking spatial self-consciousness remains rather scarce, and as such is unlikely to convince those who think that spatial self-consciousness is ubiquitous in conscious experience. Nonetheless, the cases of sensory deprivation and especially deafblindness strongly suggest that one can be conscious without being conscious of one's location with respect to one's environment. Given the dependence of spatial selfconsciousness on the processing of sensory stimuli that carry spatial information about the subject's location, and given that the capacity for consciousness does not depend on the availability of such stimuli, there is no reason to think that spatial self-consciousness should be necessary for consciousness in general. ${ }^{15}$

\footnotetext{
${ }^{15}$ Perhaps one could be in a state where one is not aware of one's location with respect one's
} 


\subsection{Consciousness without a sense of bodily ownership}

The sense of bodily ownership refers to the "phenomenological quality that [a] body part appears to be part of one's body" (Martin, 1995, p. 269). Some authors hold that ordinary conscious experience involves such phenomenology (de Vignemont, 2018), while others deny that the relevant phenomenal feature exists (Bermúdez, 2011).

Are there states of consciousness that uncontroversially lack this phenomenal feature, namely states that do not involve experiencing one's body as one's own? Proponents of the claim that the sense of bodily ownership is pervasive in ordinary experience argue that certain psychopathologies such as somatoparaphrenia and depersonalization disorder are characterized by loss of the sense of bodily ownership, over specific limbs or over the whole body respectively (de Vignemont, 2018). Somatoparaphenia is a monothematic delusion in which patients report that one of their limbs belongs not to them but to someone else. Some reports suggest that this delusional belief is rooted in phenomenology:

My eyes and my feelings don't agree, and I must believe my feelings. I know they [the affected limbs] look like mine, but I can feel they are not, and I can't believe my eyes. (Nielsen, 1938, p. 555)

Depersonalized individuals frequently report feeling disconnected from their bodies, or feeling as if their bodies were absent or dead. Unlike somatoparaphrenic patients, however, they are not delusional insofar as they do not endorse the content of these abnormal feelings (Billon, 2016). Some reports from depersonalized individuals seem to be elegantly explained by the hypothesis that they lack a sense of bodily ownership over their bodies:

My body didn't feel like my own. I just felt like a floating mind in space with blunted, blurry thoughts. I found it crazy sometimes that I even had my own body, because I didn't feel connected to it. I'd look down at my hands and they didn't feel real. (Bradshaw, 2016)

Reports from psychopathologies might not be sufficient to convince those who think that we cannot have bodily sensations without a sense of bodily ownership attached to them. There is, however, a more indirect way to argue that there can be states of consciousness lacking a sense of bodily ownership. Insofar as the putative sense of bodily ownership refers to an experience of one's body or body part as one's own, it is parasitic upon bodily awareness - which refers to one's experience of one's body in general. If a subject had no awareness of her body, then it is difficult to see how she could have a sense of bodily ownership.

environment, and yet still have bodily sensations with spatial content (e.g., an itch located in one's ankle). However, it is unclear that such sensations would involve a form of self-consciousness if they do not involve a sense of bodily ownership (see the next section). Furthermore, the deafblind subject quoted above also reported "You're not there in your body anymore [...]. The boundaries of my body vanish when [I am] cocooned in the water" (Millière, 2019, p. 271).

Millière, R. (2020). The varieties of selflessness. Philosophy and the Mind Sciences, 1(I), 8. 
There is converging empirical evidence suggesting that subjects may be conscious without having any kind of bodily experience. Examples of such states may include certain kinds of dreams and certain kinds of out-of-body experiences (generally resulting from neuropathologies). In the general population, there is evidence that a small subset of dreams completely lack bodily sensations or the representation of a dream body (Cicogna \& Bosinelli, 2001; LaBerge \& DeGracia, 2000; Occhionero \& Cicogna, 2011). For example, some subjects report that during their dreams they "experienced themselves as a disembodied point or freely moving center of awareness" (Windt, 2010, p. 301). This suggests that dreams need not involve bodily awareness, or therefore a sense of bodily ownership.

Likewise, there is a subset of out-of-body experiences (OBEs), known as "asomatic", in which subjects have the experience of being disembodied without having the illusion of seeing their own body from the outside (Alvarado, 2000; Metzinger, 2013b). A recent study with a large sample size of both healthy participants and vestibular disorder patients who reported OBEs suggests that only $10 \%$ to $30 \%$ of such experiences feature autoscopic episodes, namely the hallucination of one's "own" body in external space, at some distance from the location from which one perceives the world (Lopez \& Elzière, 2018, p. 6). This suggests that the majority of OBEs might not involve the visual representation of one's body. Thus, Alvarado (2000) reports that some individuals who experience an OBE "do not experience a body at all, describing themselves as 'pure consciousness' [...] or as 'balls of light', 'points in space', or 'clouds'” (p. 186).

Admittedly, as many as 59\% of vestibular disorder patients who reported OBEs experienced vestibular sensations concurrently (Lopez \& Elzière, 2018). However, it is dubious that mere vestibular sensations would be sufficient to sustain a sense of bodily ownership in the absence of bodily sensations located within a body schema. Indeed, vestibular sensations such as dizziness or floating sensations are not clearly instances of awareness of one's body or body parts. In any case, it is plausible that some asomatic OBEs do not involve concurrent vestibular sensations.

Overall, the evidence discussed in this section strongly supports the claim that some states of consciousness do not involve a phenomenology of bodily ownership, even if such phenomenology exists and is relatively prevalent in ordinary experience.

\subsection{Consciousness without a sense of bodily agency}

Many authors argue that there is a distinctive phenomenology of voluntary action that goes beyond the somatosensory awareness of bodily movements (Bayne, 2008; Hohwy, 2007; Horgan, Tienson, \& Graham, 2003). Assessing whether there can be states of consciousness lacking such phenomenology (if it exists) is rather straightforward.

Firstly, one should expect the sense of bodily agency to be attached to volun-

Millière, R. (2020). The varieties of selflessness. Philosophy and the Mind Sciences, 1(I), 8. 
tary bodily actions rather than to involuntary bodily movements as a general rule, although there might be some exceptions (i.e., illusions of bodily agency). There are a number of involuntary movements that should not normally be associated with a sense of agency. These include involuntary muscle twitches and reflex actions, but also passive movements resulting from the action of another agents or the force exerted by inanimate objects.

Secondly, there are countless conditions in which one's body is immobile and one lacks an experience of bodily movement altogether. Individuals in the lockedin state suffering from complete motor paralysis offer a particularly dramatic example of such a condition (Murguialday et al., 2011). But there are also mundane situations in which one is not moving a muscle, and therefore is unlikely to have any sense of bodily agency - for example as one falls asleep (see Blanke \& Metzinger, 2009).

Finally, the cases in which one lacks bodily experiences altogether (discused in subsection 3.3) should a fortiori lack any sense of bodily agency. For example, bodiless dreams should not involve a distinctive phenomenology of bodily action in the absence of a representation of a dream body.

\subsection{Consciousness without a sense of mental ownership}

The sense of mental ownership, also called sense of "mineness", refers to the putative "sense that I am the one who is undergoing an experience" (Gallagher, 2000, p. 15). Clearly one can judge, at least in some circumstances, that a conscious mental state is one's own - in the sense that one undergoes the relevant mental state. For example, I can judge that I am currently undergoing a visual experience of a computer screen, such that this token visual experience is a mental state of which I am the subject. To say that a subject has a sense of ownership over a (conscious) mental state is to say something more, namely that the subject is aware of that mental state as her own (where this awareness is not a matter of judgement, but a distinctive phenomenology of ownership).

The idea that all or almost all conscious experiences involve a sense of ownership (over those very experiences) can seemingly be found in both the analytic and the phenomenological traditions:

[A]ll subjective experience is self-conscious in the weak sense that there is something it is like for the subject to have that experience. This involves a sense that the experience is the subject's experience, that it happens to her, occurs in her stream. (Flanagan, 1992, p. 194)

When I (in nonpathological standard cases) am aware of an occurrent pain, perception, or thought from the first-person perspective, the experience in question is given immediately, noninferentially and noncriterially as mine. (Zahavi, 2005, p. 124) 
However, the sense of mental ownership is perhaps the most controversial of the six notions of self-consciousness distinguished in section 2. Firstly, some of the proponents of the idea that one is aware of one's occurrent experiences as one's own seem to understand it in a deflationary manner that amounts to little more than the claim that one's experiences constitutively contribute to one's overall phenomenology (Zahavi, 2018). If this deflationary interpretation is correct, then there is after all no distinctive phenomenology of mental ownership above and beyond the phenomenal character of one's occurrent experience. ${ }^{16}$ It is difficult to find authors who argue that there is a sense of mental ownership and explicitly refer to it as a distinctive feeling (in addition, as it were, to the phenomenal character of the mental state to which it supposedly applies). ${ }^{17}$

Secondly, a number of objections have been raised against the very idea that there is a sense of mental ownership (see Chadha, 2018; McClelland, forthcoming). Thirdly, even those who think that there is a phenomenology of mental ownership generally agree that it is not ubiquitous. Thus, some suggest that we have a phenomenology of mental ownership only in very specific cases, when we introspect our occurrent experiences (Howell \& Thompson, 2017), while others hold that the sense of mental ownership is missing at least in certain pathological cases.

Guillot (2017) and Billon (2017b) both argue that depersonalized patients lack a phenomenology of mental ownership (regardless of whether they also lack a phenomenology of bodily ownership). Consider the following reports quoted by Billon:

[I]t is not me who feels. I am not interested in what I appear to be feeling, it is somebody else who feels mechanically. (Janet, 1908, p. 515, Billon's translation)

I feel pains in my chest, but they seem to belong to someone else, not to me. (Mayer-Gross, 1935, p. 114)

Taken at face value, these reports suggest that subjects were not aware of the relevant experiences as their own. Similarly, Martin \& Pacherie (2013) suggest that

\footnotetext{
${ }^{16} \mathrm{I}$ will come back to this deflationary notion in subsection 4.4 .

${ }^{17}$ Martin \& Pacherie (2013) come close when they suggest that we normally have a "feeling or sense that our thoughts belong to us" (p. 112), but they specifically restrict their account to thoughts. Block (2007) also comes close when he writes that "awareness is a matter of having a state whose content is in some sense 'presented' to the self or having a state that is 'for me' or that comes with a sense of ownership or that has 'me-ishness' " (p. 484), although the equivalence between "awareness" and the sense of ownership suggests that Block might endorse the deflationary interpretation of the notion. Gallagher (2000) does not draw an explicit distinction between the sense of bodily ownership and the sense of mental ownership, giving as a canonical example of the "sense of ownership": "the sense that my body is moving regardless of whether the movement is voluntary or involuntary" (p. 15). This makes it difficult to understand his proposal, because being aware of one's body as one's own (through bodily experience) is different from being aware of one's bodily experience as one's own (see de Vignemont, 2011). Finally, Nida-Rümelin (2017, p. 66) argues that "being presented with something necessarily involves being [...] aware of being the subject to whom something is presented."
} 
reports of thought insertion in schizophrenia are best explained by the lack of a sense of mental ownership over affected thoughts. Here is a characteristic report quoted by Martin and Pacherie in support of their interpretation:

[S] he said that sometimes it seemed to be her own thought "but I don't get the feeling that it is". She said her "own thoughts might say the same thing", "but the feeling isn't the same", "the feeling is that it is somebody else's." (Allison-Bolger, 1999, \#89)

Of course, these reports might be best explained by the occurrence of an additional feeling of alienation or estrangement from one's experiences (in the case of depersonalization) or from one's thoughts (in the case of thought insertion) that is missing in ordinary experience (Billon \& Kriegel, 2015; Parrott, 2017). But this alternative interpretation would remove the need to posit the existence of a sense of mental ownership in the first place, suggesting that neither depersonalization/thought insertion nor ordinary experience comes with such phenomenology. ${ }^{18}$

Aside from psychopathologies, one may wonder whether more mundane states of consciousness such as nonlucid dreams and mind-wandering might offer compelling evidence that the sense of mental ownership, if it exists at all, is unlikely to be ubiquitous. Nonlucid dreams are characterized by the fact that the dreamer is not aware of dreaming. Presumably, such dreams do involve conscious experiences, in so far as there is something it is like to undergo nonlucid dreams. Admittedly, one should not confuse the awareness that one is dreaming with the awareness of one's dream experiences as one's own; in principle, one could have the latter without the former. Nevertheless, if the experience of nonlucid dreams came with a distinctive sense of mental ownership, one could expect this feature to guarantee some form of continuity and coherence in dreams; but dreams are often incongruous, vague and discontinuous (Hobson, 1988).

Mind-wandering is another ordinary scenario in which the occurrence of a distinctive sense of ownership over one's experience is implausible. As I mentioned in subsection 3.1, subjects are often unaware that they undergo episodes of mindwandering. ${ }^{19}$ The suggestion that a subject who is lost in thought and unaware of her mental drift would nonetheless have a distinctive sense of ownership over her wandering thoughts is particularly unintuitive. As Windt (2017) puts it: "mindwandering episodes are owned in the basic sense of occurring in me, they have phenomenal character [...] [b]ut this does not mean that they are also experienced [...] as mine" (p. 1727).

\footnotetext{
${ }^{18}$ It is also possible that the relevant reports are best explained by the lack of some phenomenal feature other than the putative sense of mental ownership, such as the sense of bodily ownership for depersonalization (de Vignemont, 2018) or the sense of mental agency for thought insertion (Stephens, Poland, \& Radden, 2000). While this hypothesis is compatible with the assumption that the sense of mental ownership is ubiquitous in both normal and pathological experiences, this claim requires additional motivation, which would be difficult to find if phenomenal contrast cases were unavailable.

${ }^{19}$ I do not mean to suggest that episodes of mind-wandering are not consciously experienced, but rather that subjects lack meta-awareness that they are undergoing such episodes.
} 


\subsection{Consciousness without a sense of mental agency}

While most discussions of agency focus on bodily actions, there is an increasing interest within philosophy of mind in mental actions (O'Brien \& Soteriou, 2009). Mental actions are generally taken to include various endogenous mental states such as task-related thinking, judging, calculating, deciding, actively remembering or actively imagining. Insofar as these mental states are under voluntary control and involve some degree of cognitive effort, it has been suggested that they come with a sense of mental agency (Peacocke, 2006; Proust, 2009).

According to a radical version of this view, consciousness always involves a sense of mental agency, because being conscious requires some form of mental activity:

The mind of one who is conscious is necessarily a mind actively governing the movement of its own attention and thinking processes [...].

In the final analysis it is because thinking is active and thinking is essential to consciousness that mental action is a necessary condition of consciousness. (O’Shaughnessy, 2000, pp. 89-264)

Does this view have any plausibility? Even if we assume that mental actions are normally associated with a sense of mental agency, there seem to be plenty of conscious episodes that do not involve mental activity. I have already discussed the case of schizophrenic thought insertion, which has traditionally been interpreted in terms of a lack of the putative sense of mental agency over affected thoughts, leading patients to attribute them to foreign agents (Stephens et al., 2000). But the familiar phenomenon of unbidden thoughts - thoughts that seem to pop unsolicited into one's mind - provides a more mundane example of cognitive processes lacking a sense of mental agency. While this phenomenon occurs in the general population, it is particularly common in patients diagnosed with obsessivecompulsive disorder (OCD), who struggle to keep intrusive thoughts at bay and report that their occurrence feels irresistible (Billon, 2013).

More generally, the landscape of conscious cognitive processes appears to be filled with regions of passivity. As I have previously emphasized, there is ample evidence that mind-wandering is a phenomenon that is not under voluntary control, and whose occurrence we might even fail to notice until the moment at which we snap back to reality. In light of the empirical literature on mind-wandering, it is perhaps no exaggeration to say that control of our conscious thought processes is the exception rather than the rule (Metzinger, 2013a); see also figure 2 in Metzinger (2015, p. 294). ${ }^{20}$ The same could be said about many conscious episodes that occur during nonlucid dreaming, which are often characterized by their passivity by contrast with imagination (Windt, 2017). Finally, it seems unlikely that mental actions would occur during certain states of absorption, such as the experience of being enthralled by a captivating movie.

\footnotetext{
${ }^{20}$ Although see Seli et al. (2017) for evidence that some episodes of mind-wandering are started intentionally. (I am grateful to Thomas Metzinger for bringing this article to my attention.)
} 
Overall, it does not seem difficult to find examples of conscious episodes that are characterized by a lack of mental activity, and therefore should not involve any sense of mental agency.

\subsection{The varieties of partial selflessness}

The empirical cases discussed in this section delineate many potential forms of partial selflessness, depending on how many of the six candidate notions of selfconsciousness outlined in section 2 really exist and are plausibly missing in each case given available evidence (table 1 ).

\begin{tabular}{lcccccc}
\hline Conditions & CSC & SSC & SBO & SBA & SMO & SMA \\
\hline mind-wandering & $\mathrm{X}$ & $?$ & $?$ & $?$ & $?$ & $\mathrm{X}$ \\
flow states & $\mathrm{X}$ & $?$ & $?$ & $?$ & $?$ & $?$ \\
meditation & $\mathrm{X}$ & $\mathrm{X}$ & $?$ & $?$ & $?$ & $?$ \\
nonlucid dreams & $\mathrm{X}$ & $?$ & $?$ & $?$ & $\mathrm{X}$ & $\mathrm{X}$ \\
bodiless dreams & $\mathrm{X}$ & $?$ & $\mathrm{X}$ & $\mathrm{X}$ & $\mathrm{X}$ & $\mathrm{X}$ \\
deafblindness & $?$ & $\mathrm{X}$ & $?$ & $?$ & $?$ & $?$ \\
sensory deprivation & $?$ & $\mathrm{X}$ & $?$ & $?$ & $?$ & $?$ \\
asomatic OBEs & $?$ & $?$ & $\mathrm{X}$ & $\mathrm{X}$ & $?$ & $?$ \\
somatoparaphrenia & $?$ & $?$ & $\mathrm{X}$ & $\mathrm{X}$ & $?$ & $?$ \\
drug-induced states & $?$ & $?$ & $\mathrm{X}$ & $\mathrm{X}$ & $?$ & $?$ \\
depersonalization & $?$ & $?$ & $\mathrm{X}$ & $\mathrm{X}$ & $\mathrm{X}$ & $?$ \\
total paralysis & $?$ & $?$ & $?$ & $\mathrm{X}$ & $?$ & $?$ \\
thought insertion & $?$ & $?$ & $?$ & $?$ & $\mathrm{X}$ & $\mathrm{X}$ \\
unbidden thoughts & $?$ & $?$ & $?$ & $?$ & $?$ & $\mathrm{X}$ \\
\hline
\end{tabular}

Table 1: The varieties of (partial) selflessness. (CSC $=$ cognitive self-consciousness, SSC = spatial self-consciousness, $\mathbf{S B O}=$ sense of bodily ownership, SBA = sense of bodily agency, SMO = sense of mental ownership, SMA = sense of mental agency. Red crosses denote the absence of the relevant feature.) As I have repeatedly emphasized, several of these putative forms of self-consciousness might not exist. Rather than weighing directly on their existence, I have argued - against $\mathbf{N C}_{\mathbf{1}}$ $\mathbf{N C}_{6}$ - that for each of these notions of self-consciousness, it is plausible in light of available evidence that (at least) some states of consciousness lack the corresponding phenomenal feature.

If several of the putative forms of self-consciousness (1-6) exist, however, then there might be not only different types of partially selfless state that differ with respect to the feature they lack, but also totally selfless states: states that lack any form of self-consciousness. I will now consider this possibility in light of empirical evidence, and discuss potential objections to the very idea of totally selfless states of consciousness. 


\section{Total selflessness}

I have previously defined totally selfless states of consciousness as follows:

TSL A global state of consciousness of a subject $S$ is totally selfless if and only if, while being in that state, $S$ is not self-conscious in any way in which $S$ can be self-conscious (if $S$ can be self-conscious at all).

Several authors have argued that totally selfless states of consciousness are at least conceptually possible, if not nomologically possible. Thus, Peacocke (2014) suggests that there could be subjects whose (conscious) mental states are at "Degree 0" of self-representation, meaning that they do not involve any kind of selfrepresentation. Although he notes that "there is nothing incoherent in this description of a subject at Degree 0 who perceives the world but does not self-represent" (Peacocke, 2014, p. 31), and entertains the fictional case of "spherical underwater creature" as an example, he falls short of endorsing the claim that any actual creature has Degree 0 conscious mental states.

Likewise, Dainton (2016) considers as a thought experiment the case of newly born deafblind puppy floating in outer space, arguing that such creature would have experiences lacking self-consciousness altogether. While he acknowledges that this kind of fictional scenario is "rather speculative", he suggests that it there is no alternative to speculation when it comes to the possibility of totally selfless states, because such states are dramatically different from the wakeful states we are familiar with.

In this section, I will argue that we need not resort to far-fetched thought experiments to ascertain whether totally selfless states are nomologically possible. Indeed, I will suggest that there might be actual examples of such states in healthy, neurotypical adult humans - although perhaps not in ordinary conscious experience. ${ }^{21}$ I will specifically discuss available evidence regarding three candidates for such states: drug-induced ego dissolution, meditation and lucid dreamless sleep. After discussing each of these cases, I will address four lingering objections to the possibility and reportability of totally selfless states. ${ }^{22}$

\subsection{Drug-induced ego dissolution}

Certain psychoactive drugs are known to produce dramatic short-term effects on self-consciousness, especially at higher doses. This phenomenon, called drug-induced ego dissolution (DIED), is typically described as a (reversible) loss

\footnotetext{
${ }^{21}$ Whether these examples really are totally selfless states of consciousness depends, of course, on whether the typology of self-consciousness proposed in section 2 is exhaustive. On this issue, see my response to the third objection in section 4.4 below.

${ }^{22}$ I remain agnostic here on whether there might be several types of totally selfless state of consciousness, or a single type of such state - although I am personally inclined to believe that the former is true, as the putative examples of totally selfless states discussed below seem to vary with respect to phenomenology.
} 
of one's sense of self and sense of self-world boundaries (Letheby \& Gerrans, 2017; Millière, 2017). ${ }^{23}$ Although such effects had already been reported in early studies on mescaline ${ }^{24}, \mathrm{LSD}^{25}$ and psilocybin ${ }^{26}$, recent controlled studies and anecdotal evidence converge in suggesting that they can be induced by a broad range of psychoactive drugs, including serotonin 2A agonists (so-called classic psychedelics), NMDA antagonists (so-called dissociative anesthetics) and kappa-opioid agonists. ${ }^{27}$

A careful analysis of reports of DIED suggests that this notion is a complex construct that refers to a family of experiences rather than a single type of experience. While some self-reported experiences of DIED are described as involving a loss of access to autobiographical semantic information (e.g., information about one's personal identity and history), others are characterized by the loss of awareness of bodily sensations, and yet others seem to involve distinct impairments. If there are several forms of self-consciousness, then it should not be surprising that different types of experiences might be indiscriminately reported as experiences of "self-loss", even though they are in fact characterized by the loss of distinct phenomenal features. In other words, DIED might be an umbrella term that covers different forms of partial selflessness (Millière et al., 2018). Instead of using the term indiscriminately, it is more judicious to assess which putative forms of self-consciousness might be present or absent in experiences induced by different drugs.

Intriguingly, some reports of DIED describe experiences that appear to lack not one or a few of the putative forms of self-consciousness outlined in section 2, but all six of them. One drug called 5-MeO-DMT seems to be particularly likely to induce this kind of experience (Barsuglia et al., 2018; Uthaug et al., 2019). 5$\mathrm{MeO}-\mathrm{DMT}$ is a classic psychedelic naturally occurring in the toxin of the toad Bufo alvarius as well as in a wide variety of plants. Its effects are both very intense and very short-lived, lasting for 10 to 20 minutes when the substance is insufflated. Let us examine reports of DIED in light of the distinction between six notions of self-consciousness, with a particular focus on reports describing the effects of 5-MeO-DMT.

I have already argued that large parts of our waking lives are not spent thinking about ourselves. This is all the more likely to be the case under the influence of drugs that profoundly impair cognitive processes. Consider the following descriptions of the effects of 5-MeO-DMT gathered from Erowid, a curated database of reports of drug-induced states: ${ }^{28}$

\footnotetext{
${ }^{23}$ See also Letheby (2020) and Deane (2020), both in this special issue.

${ }^{24}$ Beringer (1927; Guttmann \& Maclay, 1937; Mayer-Gross \& Stein, 1926).

${ }^{25}$ Anderson \& Rawnsley (1954; Bercel, Travis, Olinger, Dreikurs, \& Polos, 1956; Klee, 1963; Pahnke \& Richards, 1966; Savage, 1955; Sedman \& Kenna, 1964; Von Mering, Morimoto, Hyde, \& Rinkel, 1955).

${ }^{26}$ Pahnke (1966; Rümmele \& Gnirss, 1961).

${ }^{27}$ See Millière (2017) for a review.

${ }^{28}$ See erowid.org/experiences (each report has a unique identification number).
} 
I recall no thought process, I wasn't thinking at all, just simply experiencing. (\#17378)

The world as I knew it is gone forever [...]. There is no thought. There is no time. There is no world. (\#90018)

My brain seemed unable to comprehend the detail of complexity and I wondered if my vision was temporarily impaired. My ability to think coherently seemed to be similarly truncated. (\#79324)

It's impossible to think while undergoing the experience. (\#52311)

My thoughts shattered into nothing. I lost sense of self, and my environment [...]. [I]t was [an] absence of conscious thought. (\#16507)

Darkness surrounds me entirely, yet I'm not unconscious. I'm aware of the darkness, but there isn't any mental chatter. I wasn't wondering where I was [...]. I wasn't wondering what had happened to anything, or anyone that were with me a moment ago. Just silence and darkness. (\#90196)

These reports suggest that at the peak of experiences induced by $5-\mathrm{MeO}-\mathrm{DMT}$ it becomes difficult to think at all. A fortiori, one should expect that most subjects are unable to think about themselves as themselves in that state.

There is also evidence that the experience of space is thoroughly disrupted by 5-MeO-DMT. A recent online survey on the effects of the drug with a sample of 515 participants found that the overwhelming majority of respondents scored positively on items of the Mystical Experience Questionnaire corresponding to "Loss of your usual sense of space" (95\% of respondents), "Loss of usual awareness of where you were" (88\%) and "Being in a realm with no space boundaries" (87\%) (Davis, Barsuglia, Lancelotta, Grant, \& Renn, 2018). Anecdotal reports from Erowid also suggest that subjects often lack awareness of their location in space:

[S]oon I am falling, falling, up, down, inward, outward, I'm not really sure. I am flung into a room with no features and no depth cues. (\#5816)

I was the universe, I was everywhere and nowhere, everything and nothing all at the same time. (\#49690)

Any concept of "time" or relative "space" [...] was carried off along with the rest of manifest existence [...] moving my consciousness inward and outward in unimaginable magnitude, "eventually" into the yawning maw of Nothingness [...]. All sense of "I" [was] instantly gone. (\#23769)

I previously argued in subsections 3.3 and 3.4 that one cannot have a sense of bodily ownership or a sense of bodily agency if one lacks bodily experiences altogether. Reports from 5-MeO-DMT frequently describe a complete loss of bodily awareness. For example, the following reports seem to describe a lack of both spatial selfconsciousness and bodily awareness: 
I was completely disconnected somatically, unable to locate or feel my body [...] unable to locate myself - or anything else - anywhere in particular. I had no body, not even the slightest semblance of a dreambody or mental-body, and I had absolutely no sense of where I was. (Masters, 2005)

"I" was no more, blasted to a confetti cloud by an explosive force I could no longer locate in my head, because it had exploded that too, expanding to become all that there was. Whatever this was, it was not a hallucination. A hallucination implies a reality and a point of reference and an entity to have it. None of those things remained [...]. And then suddenly the devolution of everything into the nothingness of pure force reverses course. One by one, the elements of our universe begin to reconstitute themselves: the dimensions of time and space returned first, blessing my still-scattered confetti brain with the cozy coordinates of place; this is somewhere! And then I slipped back into my familiar "I" like an old pair of slippers and soon after felt something I recognized as my body begin to reassemble. (Pollan, 2018)

These reports and many others suggest that at the height of the 5-MeO-DMT experience subjects may lose all awareness of their bodies. Consequently, they should also lack a sense of bodily ownership and a sense of bodily agency.

What about the sense of mental ownership and the sense of mental agency? It is easier to start with the latter: As we have seen, the putative sense of mental agency depends upon the occurrence of mental actions. During an experience as intense, chaotic and uncontrollable as that elicited by 5-MeO-DMT, in which it becomes difficult even to think, there should not be much room for mental activity. Subjects almost unanimously report on their complete passivity as they go through the experience as if riding a particularly terrifying rollercoaster. A common occurrence in the reports is that one has to "let go" of control over what is happening in one's mind and "surrender" to the experience. ${ }^{29}$ Thus, it is reasonable to assume that experiences induced by 5-MeO-DMT rarely if ever involve a sense of mental agency.

It is more difficult to assess whether these experiences involve a sense of mental ownership because the notion is delicate to grasp. Are subjects under the influence of 5-MeO-DMT aware of their experience as their own? Presumably, being aware of one's experience as one's own involves having a sense that one is the subject of one's experience. This seems to require the ability to distinguish between the experience one is having and oneself as its subject. Reports of DIED frequently mention that such states precisely lack a sense that one is having the experience:

\footnotetext{
${ }^{29}$ One report from the Erowid database contains this characteristic piece of advice: "I would, personally, advise any potential user of this drug to simply be psychologically prepared to let go, and surrender ego and control, and accept that, once its effects are in full motion, it is absolutely impossible to grasp any control of your own life and consciousness, feeling utterly helpless and in vulnerable awe. It will be overwhelming” (\#82407).
} 
It felt as if "I" did no longer exist. There was purely my sensory perception of my environment, but sensory input was not translated into needs, feelings, or acting by "me".

(report cited in Millière et al., 2018, p. 10)

Online reports from Erowid also emphasize this form of extreme absorption in the experience induced by 5-MeO-DMT, precluding any awareness of oneself as the experience's subject:

There was no self, nothing to separate me from the sensation. (\#81888)

I had no idea which part of what was happening or what I was seeing was “me". (\#112103)

I had previous experience with [other] hallucinogens [...] and had always felt able to differentiate and mediate between the experience and the "I" as its subject [...]. This time, however, the experience was relentless and psychologically brutalizing. (\#49107)

These reports cast doubt on the claim that the putative sense of mental ownership could endure in some of the experiences induced by 5-MeO-DMT.

Overall, the evidence reviewed here supports the claim that DIED, and specifically the kind of experience elicited by 5-MeO-DMT, can lack any of the six putative forms of self-consciousness discussed in this article. Consequently, such experiences are good candidate examples of total selflessness as I have defined it. $^{30}$

\subsection{Meditation}

Some meditation practices aim specifically to induce an experience of total selflessness, in particular so-called non-dual awareness meditation and samādhi meditation. Non-dual awareness meditation loosely refers to a family of practices that can be found in several Eastern contemplative traditions, including Dzoghen and Mahāmudrā within Tibetan Buddhism, and Advaita Vedanta and Kashimiri Shaivism within Hinduism (Dunne, 2011; Josipovic, 2010). These practices rely upon the assumption that ordinary conscious experience is structured by a dichotomy between subject and object, which can be momentarily dispelled by expert meditators. Such practice is meant to reduce the phenomenal character of one's experience to a bare minimum, and remove any form of intentionality; in this state, allegedly, "non-dual awareness appears as an empty cognizance, aware and present, but without any thoughts, emotions or perceptions, without a sense of body, space, orientation, time or the usual sense of self" (Josipovic, 2019, p. 7).

\footnotetext{
${ }^{30}$ Another possibility to consider is that all six kinds of self-consciousness might disappear in the relevant drug-induced states, but in succession rather than simultaneously, such that those states would always involve at least one form of self-consciousness. However, I think this interpretation is particularly implausible in light of available reports.
} 
Samädhi is a meditative practice from the Buddhist tradition that aims at inducing a state of deep absorption (Shankman, 2008). The practice of samädhi includes several stages (or in Pāli, jhāna), culminating in a "formless" or "objectless" state. The aim of this practice is to reach a kind of "lucid trance" (Harvey, 2012, p. 330), a state of pure consciousness which involves a complete loss of self-consciousness: "attaining samädhi is to reach the silent state of pure consciousness where there is no phenomenological content and a loss of any sense of individual self or duality" (Wahbeh, Sagher, Back, Pundhir, \& Travis, 2018). Rather than lacking phenomenal character altogether (which could be a contradiction in terms), experiences induced by samädhi might simply lack ordinary conscious contents, including the forms of self-consciousness that might pervade ordinary experience.

Canonical descriptions of altered states of consciousness from ancient contemplative traditions cannot be taken at face value without further scrutiny. Nonetheless, reports from advanced meditation practitioners intriguingly suggest that it is possible to reach states of deep absorption that lack the six putative forms of self-consciousness discussed in section $2 .{ }^{31}$ Thus, samādhi practice is said to induce experiences that should lack cognitive self-consciousness in so far as they are "free from discursive thought" (Shankman, 2008, p. 44). ${ }^{32}$ In such experiences, "all limitations imposed by the concept of 'space' are given up" (Patel, 2012, p. 352); "awareness of the body falls away, leaving only the experience of limitless space" (Shankman, 2008, p. 50). The Buddhist monk and expert meditator Ajahn Brahmavamso further describes the experience of samädhi meditation in the following terms: "The first jhāna is when the body and the five senses have disappeared [...] in the second jhanna your will has disappeared. It is not just that you do not want to do anything. You cannot do anything [...]. It is quite clear that in jhānas you cannot feel anything to do with the body" (Shankman, 2008, pp. 169-173).

These anecdotal reports are consistent with reports from controlled studies with advanced meditators describing experiences that lack spatial self-consciousness and bodily awareness (Ataria et al., 2015; Dor-Ziderman, Berkovich-Ohana, Glicksohn, \& Goldstein, 2013; Millière et al., 2018). Interestingly, a recent qualitative study of 59 meditation-related experiences described during semi-structured interviews found that three quarters of these experiences involved disruptions of self-consciousness, including "loss of sense of agency" (25\%), "loss of sense of basic self" (25\%), "change in sense of embodiment" (22\%), "change in narrative self" (22\%) and "loss of sense of ownership" (18\%) (Lindahl, Fisher, Cooper, Rosen, \& Britton, 2017). Specifically, the authors report that a number of meditation-related experiences involved "fundamental changes in [the practitioners'] sense of self [...] such that they felt like they no longer existed at all” (Lindahl et al., 2017, p. 20).

Admittedly, the hypothesis that some meditation practices can induce states of

\footnotetext{
${ }^{31}$ See also Metzinger (2020, this issue).

${ }^{32}$ See also: "Crucial to the content-less jhānas are the absence of discursive reasoning and thought, and the cessation of the activities of mind" (Patel, 2012, p. 352).
} 
consciousness entirely lacking self-consciousness remains tentative. It difficult to find detailed descriptions of such states, especially from controlled studies; and the theory-ladenness of traditional descriptions of meditative states might raise some concerns regarding their validity. Nevertheless, existing reports warrant further investigation into the phenomenology of specific types of meditation, in particular non-dual awareness and samādhi.

\subsection{Lucid dreamless sleep}

It has recently been suggested that conscious episodes may occur during sleep outside of dreams, and that such episodes may lack any kind of self-consciousness (Thompson, 2015; Windt, 2015b; Windt, Nielsen, \& Thompson, 2016). In the context of this hypothesis, dreams are defined as immersive spatio-temporal hallucinations, namely non-veridical perceptual experiences that involve the sense of being present in a simulated environment (Windt, 2010). Thus, a conscious experience occurring during sleep would qualify as "dreamless" if it lacked the immersive character of dreaming, as well as any specific imagery.

The idea that consciousness might persist during dreamless sleep can be traced back to classical discussions in Indian philosophy, particularly in the Advaita Vedānta and Yoga schools (Thompson, 2015). The modern practice of yoga nidrā (or "yogic sleep") is claimed to induce a conscious experience of "witnessing sleep" in the absence of dreams (Parker, 2019). However, this claim has not been rigorously assessed in controlled studies (Parker, 2017). While there is some evidence that lucid dreaming is more frequent in long-term meditators than in meditation-naïve individuals (Baird, Riedner, Boly, Davidson, \& Tononi, 2019), there is no evidence that meditators can remain conscious in sleep outside of dreams, other than anecdotal reports often associated with dubious parapsychological claims (Bharati, 2014; although see Alcaraz-Sanchez, 2019).

An interesting avenue of research for the investigation of consciousness during deep sleep is the study of so-called "white dreams" in the laboratory. White dreams refer to cases in which subjects waking from sleep report the feeling of having been dreaming prior to awakening, but are unable to recall any details about these putative dreams. As many as a third of post-awakening reports in serial-awakening studies describe white dreams (Siclari, Larocque, Postle, \& Tononi, 2013). According to the standard interpretation of such cases, subjects do report the occurrence of contentful dreams whose contents they simply forgot upon awakening. However, it has been suggested that a subset of such reports might accurately describe conscious episodes occuring during dreamless sleep, without sensory or propositional content. On this interpretation, "subjects experience only a minimal form of conscious presence with no narrative structure, and no specific percepts, bodily sensations or thoughts occurring during such experiences" (Fazekas, Nemeth, \& Overgaard, 2019, p. 85). This kind of conscious episode might occur specifically during the transition from unconscious sleep to immersive dreaming (Windt et al., 2016).

Millière, R. (2020). The varieties of selflessness. Philosophy and the Mind Sciences, 1(I), 8. 
Interestingly, there are many anecdotal reports from lucid dreamers suggesting that some episodes of lucidity during sleep can be completely devoid of imagery (Bogzaran, 2003; Hurd, 2008; Magallon, 1987). These episodes are often reported to occur either at the onset of lucid dreaming or during the transition between the end of one contentful dream and the beginning of the next one. Anecdotal reports often describe these lucid episodes as the experience of a "void":

I found myself in an empty void [...]. I had no body and my consciousness was sort of floating there. ${ }^{33}$

The void as I've experienced it is a state beyond self-concept and selfawareness. It exists as a sense of pure awareness without any perceiver (as such), no sense of personal self or egoic point of focus [...]. Within the void state of a lucid dream, "I" ceased to exist as "myself" $[\ldots]$ without any sense of "me" having the experience. ${ }^{34}$

Whether or not such experiences should be considered to be (minimalistic) lucid dreams rather than lucid dreamless sleep is debatable, since some descriptions suggest that they retain the immersive character of dreams (see Windt, 2015a, Chapter 11). If subjects do feel "immersed" within an empty space with no visual features, one may also wonder whether they might retain some form of spatial self-consciousness during these episodes. While reported experiences of the "void" involve no depth cues and often lack bodily sensations, it is possible that subjects still have a sense of the spatial structure of their environment and their location within it. Yet it seems that at least some of these reports describe conscious episodes that lack any kind of spatial content. Windt has argued on the basis of similar reports that such experiences might be characterized by "pure subjective temporality", meaning that their phenomenal character would be reduced to the mere phenomenology of "now-ness" and duration (Windt, 2015b). To the extent that the relevant conscious episodes lack propositional thoughts, sensory content and spatial content, they should lack all the putative forms of self-consciousness distinguished in section 2 .

While anecdotal reports offer intriguing clues about the range of conscious experiences that can occur during sleep, it is important to note that the occurrence of lucid dreamless sleep has not yet been systematically investigated in the laboratory. Future research using a serial-awakening paradigm with subjects who report frequent lucid episodes without imagery during sleep might shed further light on whether it is possible to remain conscious during dreamless sleep.

\footnotetext{
${ }^{33}$ Report retrieved from https://www.reddit.com/r/LucidDreaming/comments/411nr9/found_som e_kind_of_black_void_while_wilding.

${ }^{34}$ Report retrieved from https://www.reddit.com/r/LucidDreaming/comments/nuam2/trapped_i n_your_own_mind_and_the_void.
} 


\subsection{Objections and replies}

I have discussed so far tentative evidence that totally selfless states of consciousness may actually occur under various conditions. Given that the relevant reports remain anecdotal, however, they may not be sufficient to convince proponents of the claim that self-consciousness is necessary for consciousness. To address this concern, I will now consider four objections to the possibility and reportability of totally selfless states of consciousness.

Objection 1. There can be no experience of total selflessness, because there is no experience without a subject of experience.

This objection appears to rest upon a category mistake. The claim that "there is no experience without a subject of experience" (Frege, 1921/1956, p. 299, translation modified) pertains to the metaphysics of experience, and does not have implications for phenomenology: it states that every experience has an experiencing subject as its bearer. This claim does not entail that the subject of a conscious experience need be conscious of herself as herself. To say that experiences can be totally selfless, as I have previously defined this notion, is not to say that experiences can be "free-floating" and exist without a subject of experience. The relevant notion of selflessness pertains to the absence of self-consciousness - construed as a phenomenal notion - rather than to the absence of a subject of experience.

Objection 2. There can be no experience of total selflessness, because it would be an experience devoid of content, and no experience can be contentless.

There is a lingering ambiguity about the notion of content in this objection. The notion of "phenomenal content" is occasionally used as a synonym for the phenomenal character of an experience, or what it is like to have that experience (McGinn, 1989, p. 66). It is trivially true that there can be no conscious experience without content in that sense, insofar as any conscious experience is such that there is something it is like to have it. Consequently, a conscious episode lacking any kind of self-consciousness should still have phenomenal character.

Admittedly, some of the tentative examples of totally selfless states I have discussed are meant to involve extreme forms of absorption and sensory gating, resulting in a dramatically impoverished phenomenology compared to ordinary conscious experience. Nonetheless, they must have a phenomenal character in order to be conscious states at all. There is nothing inconsistent in the idea of a totally selfless state that has phenomenal character, because consciousness does not constitutively involve consciousness of oneself as oneself.

Secondly, the notion of content commonly refers to intentional content rather than phenomenal character. Whether or not a conscious experience can completely lack intentional content is a controversial question. It is true that the descriptions of some states induced by non-dual awareness meditation or samādhi, 
for example, suggest that such states lack intentional content altogether. But even if this characterization were inaccurate - even if there could be no conscious experience without intentional content - it would not entail that the relevant states should involve a form of self-consciousness.

There is no reason why the possibility of totally selfless states should rest upon the possibility of conscious states without intentional content. Totally selfless states as I have defined them - states of consciousness lacking any form of selfconsciousness - need not be "minimal phenomenal experiences" defined as experiences lacking intentionality (Metzinger, 2018; Windt, 2015b). Interestingly, some descriptions of drug-induced ego dissolution involve rich sensory phenomenology, including intense visual hallucinations that presumably have intentional content (Millière, 2017). Consider also this intriguing report of an acute psychotic episode involving perceptual content:

Consciousness gradually loses its coherence. One's center gives way. The center cannot hold. The "me" becomes a haze, and the solid center from which one experiences reality breaks up like a bad radio signal. There is no longer a sturdy vantage point from which to look out [...]. No core holds things together [...]. Random moments of time follow one another. Sights, sounds, thoughts, and feelings don't go together. (Saks, 2007, p. 13)

While this anecdotal report is too coarse-grained to assess whether it describes an episode that plausibly lacks any form of self-consciousness, it is least conceivable that a similar experience with intentional content could be totally selfless.

Objection 3. There is a form of self-consciousness that is more basic than any of the six notions of self-consciousness discussed in this article and is preserved in allegedly "selfless" states.

This is an important objection that deserves careful consideration. Among authors who argue that there are several forms of self-consciousness, many consider that these features can be ordered such that there is a most minimal or most basic form of self-consciousness. One can find a number of different labels referring to such a notion in the literature, including "minimal self" (Zahavi, 2010), "minimal phenomenal selfhood" (Blanke \& Metzinger, 2009) and "basic self-awareness" (Billon, 2017a). What it means for a form of self-consciousness to be more "minimal" or "basic" than any other is not always explicitly spelled out, although it generally means that such a feature is the most ubiquitous form of self-consciousness in conscious experience.

Some authors argue that the most minimal form of self-consciousness is one of the six features distinguished in section 2 . This is the case for proponents of a version of the Necessity Claim (NC) with respect to one (but not all) of these features: if a form of self-consciousness is necessary for consciousness in general, then it is more basic than any other form of self-consciousness that may exist. Some propo- 
nents of the Typicality Claim (TC) also hold that one of the six relevant features is more pervasive the others. For example, Metzinger (2013b) and Windt (2015a) argue that spatial self-consciousness is the most minimal form of self-consciousness, because it remains present even when all the other forms of self-consciousness are missing - although spatial self-consciousness can itself go missing in totally selfless states of consciousness. ${ }^{35}$

Others suggest, however, that the most minimal form of self-consciousness is not reducible to any of the six notions distinguished in section 2; instead, they argue that it is a distinct notion variously referred to as "pre-reflexive self-awareness" (Zahavi, 1999, 2005, 2014) or "for-me-ness" (Kriegel, 2009; Zahavi \& Kriegel, 2016). This notion denotes the subject's awareness of her occurrent experience rather the subject's awareness of herself (as herself). To mark this distinction, this notion is occasionally referred to as a non-egological conception of self-consciousness (Gurwitsch, 1941). Zahavi and Kriegel themselves acknowledge that for-me-ness should not be conflated with self-consciousness as it is typically defined:

For some, to be self-conscious is to think of oneself as oneself, or to be aware of one's states or features as one's own [...]. Clearly, on such understandings of the term "self-consciousness", it would be quite implausible to suggest that all phenomenal consciousness involves prereflective self-consciousness. It should be clear, however, that this is not how we understand the notion of an experiential for-me-ness. ${ }^{36}$ (Zahavi \& Kriegel, 2016, p. 40)

Accordingly, the objection that every experience involves self-consciousness in the form of for-me-ness appears to stem, at least in part, from a verbal dispute. Even if we grant the claim that pre-reflective self-consciousness or for-me-ness is constitutive of consciousness, it does not follow that totally selfless states of consciousness - as I have defined them - are impossible. A subject could be aware of her occurrent conscious experience (i.e., have for-me-ness), yet fail to be aware of herself as herself(Guillot, 2017). Such a subject would be in a totally selfless state, defined as a state lacking any form of self-consciousness sensu stricto, i.e. egological self-consciousness. ${ }^{37}$

Perhaps one could object that there is yet another notion of self-consciousness, distinct both from for-me-ness and from the six notions outlined in section 2 , that is instantiated even in alleged examples of totally selfless states. ${ }^{38}$ Specifically, one

\footnotetext{
${ }^{35}$ For a criticism of the claim that spatial self-consciousness is always instantiated whenever any other form of self-consciousness is instantiated, see Millière (2019).

${ }^{36}$ See also Zahavi (2018, p. 706): "being aware of one's experiences when they occur is [not] tantamount to being aware of oneself as a (secondary) object [of one's experience]".

${ }^{37}$ In my opinion, referring to the non-egological notion as "self-consciousness" is somewhat misleading, because this term naturally refers to the subject's consciousness of herself - just as "time consciousness" and "bodily consciousness" typically refer to the subject's consciousness of time and of her body respectively.

${ }^{38}$ Due to lack of space, I have left out of my discussion notions that are occasionally presented
} 
could argue that there is after all such a thing as a sui generis qualitative property of selfhood that is more basic than the specific features discussed so far and irreducible to any of them.

I find this proposal implausible for two reasons. Firstly, the notion of a sui generis qualitative property of selfhood seems utterly mysterious. As I pointed out at the start of this paper, there is a widespread agreement that no such feature can be found through introspection. Part of the problem is that it is unclear what one should look for if one were attempting to detect the presence of a sui generis qualitative property of selfhood in one's experience. Secondly, even if it were possible to detect such a feature in ordinary conscious experience, there would be no reason to think that the tentative examples of selfless states of consciousness I have discussed instantiate it. Indeed, many of the relevant reports are quite explicit about the fact that the described experiences lack any feature that could be described as a sense of self. Consider, for example, these additional reports of experiences induced by 5-MeO-DMT, retrieved from Erowid:

I was completely disassociated from the "real world" and [from] any sense of self. It was the most jarring feeling. (\#107905)

It is a complete annihilation of self [...]. I was absolutely nothing but a sensory perceiver, stuck within the split seconds that were eternity. (\#18198)

It felt as if all of the atoms of the molecules that typically form my physical self simply dispersed, and even my sense of self, or ego, vanished [...]. (\#56384)

I wasn't me any longer. There was no me. There was no ego. (\#27601)

The interpretation of such anecdotal reports can be debated. Nonetheless, it is prima facie implausible that the reported experiences did involve a sui generis qualitative property of selfhood to which subjects were oblivious. Given that there is no obvious evidence for the claim that all experiences - including tentative examples of totally selfless states - involve a sui generis qualitative property of selfhood, the burden of proof is on proponents of this claim.

as "social" or "interpersonal" forms of self-consciousness (e.g. Zahavi, 2014). However, these notions often seem reducible to one of the six forms of self-consciousness I have distinguished. For example, the conscious thought that I am less proficient in Chinese language than someone else is an instance of cognitive self-consciousness. One notable exception might be the category of so-called self-conscious emotions (such as shame, pride and guilt), which does not seem reducible to any of the six features discussed in this article (Sznycer, 2019); but it is very plausible that such emotions are lacking from most states of consciousness. (Thanks to Dan Zahavi for raising this point.) 
Objection 4. There can be no autobiographical memory of totally selfless states, therefore reports of such states are suspect.

This line of objection can be found in the following passage from Metzinger: ${ }^{39}$

Autophenomenological reports given by human beings about selfless states [...] will typically not impress philosophers much, because they contain an inherent logical fallacy: How can you coherently report about a selfless state of consciousness from your own, autobiographical memory? (Metzinger, 2003, p. 566)

Let us unpack this remark. To begin with, it is not obvious that the relevant reports contain a logical fallacy. Take the report quoted above: "There was no me. There was no ego." This report would be self-contradictory if it could be paraphrased as "I had an experience without a subject of experience" or even "I had an experience that I did not have". However, this is clearly not the intended meaning of the report. Rather, by "me" and "ego", the author of the report appears to refer within the context of the quote to a phenomenal feature, namely to some form of self-consciousness (or indeed, to any form of self-consciousness). ${ }^{40}$ This is more obvious in other reports quoted above, such as "my sense of self, or ego, vanished".

However, the primary target of Metzinger's remark is not the logical consistency of the relevant reports per se, but their status as recollections of past experiences. Specifically, the comment suggests that reporting a past conscious experience as totally selfless on the basis of an autobiographical memory is a form of confabulation. This suggestion seems premised upon the assumption that a conscious episode must involve some form of self-consciousness in order to be stored and later retrieved as an autobiographical memory. While a systematic discussion of the relationship between memory and self-consciousness is beyond the scope of this paper, I will succinctly argue that this assumption is unfounded. ${ }^{41}$

First of all, there is no agreement on how to define autobiographical memory, or how it relates to the standard taxonomy of declarative memory. For some, autobiographical memory forms a subset of episodic memory, namely memory of particular events from one's past (Bermúdez, 2017), while others argue that autobiographical memory also includes a subset of semantic memory, namely general knowledge about oneself (Conway, 2005). In any case, retrospective reports of totally selfless states present themselves as reports of episodic rather than semantic memories, insofar as they describe a specific conscious episode from the subject's past.

\footnotetext{
${ }^{39}$ As far as I know, the gist of the objection dates back to much older debates in Buddhist philosophy (Chadha, 2019; Robins, 2017).

${ }^{40}$ Compare this with a subject reporting that "there was no time" during an intense meditation practice: clearly, such report would not be intended to mean that the relevant experience did not unfold in time, but rather that it did not include a phenomenology of duration.

${ }^{41}$ See Bermúdez (2017) for an overview of the relationship between memory and self-consciousness. See also Fink (2020, this issue).
} 
However, there is a further disagreement as to whether all episodic memories are autobiographical. ${ }^{42}$ Thus, Bermúdez (2017) argues that remembering an event such as the decisive goal of a football match by recalling an image seen on television is an instance of non-autobiographical episodic memory, because it is not specifically about oneself and one's past (although it originates in an episode of one's personal history). Along the same lines, one could attempt to fend off Metzinger's concern by arguing that reports of totally selfless states are recollections of episodic but not autobiographical memory. The success of this strategy depends on how one cashes out the criterion that autobiographical memory be specifically about oneself and one's past. While putative memories of totally selfless states do originate in past conscious episodes, one might argue that they are not specifically about oneself in the relevant sense, because the recollected conscious episodes allegedly lacked any form of self-consciousness.

Regardless of how autobiographical memory is defined, the crux of Metzinger's concern seems to be the fact that putative memories of totally selfless states are reported in the first person, as memories of experiences that one lived through even though such experiences supposedly did not involve any awareness of oneself. There are several ways to address this concern. First, it is worth noting that a number of reports of putative selfless states precisely avoid using the first-person pronoun, or explicitly point out its inadequacy: ${ }^{43}$

There existed no one, not even me [...] so would it be proper to still speak of "I", even as the notion of "I" seemed so palpably illusory? (Erowid report \#42740, psychoactive compound: psilocybin)

Everything is slipping away [...] and then I'm gone [...]. I use the word "I" after-the-fact. At the time, I was no longer aware of my separate existence [...]. (\#95305, psychoactive compound: ketamine)

[K]eep in mind, at this point, [that] I wasn't aware of my own existence, so "I" isn't the best word to use. (\#32064, psychoactive compound: 4-Acetoxy-DiPT)

[T]he use of the pronoun "I" to describe the experience is completely inappropriate [...]. (\#61129, psychoactive compound: salvinorin A)

While many reports do use the first-person pronoun, such use need not be interpreted as evidence that subjects were self-conscious during the recollected experience. Rather, grammatical conventions dictate that using the first-person pronoun to report episodes of one's past is more appropriate than using convoluted impersonal constructions. On most accounts of episodic memory, at least three distinct mental states are involved in the process that leads from the occurrence of a con-

\footnotetext{
${ }^{42}$ For example, Hoerl (1999) endorses the claim that all episodic memories are autobiographical.

${ }^{43}$ Billon also points out that "patients suffering from severe forms of depersonalization, can express reluctance to use the first-person and even, in delusional cases, avoid it altogether, referring to themselves in the third-person exclusively" Billon (2017a, p. 1).
} 
scious experience to the retrospective report of that experience: (a) the original experience that is reported upon, (b) the representation of that experience retrieved during recollection, and (c) the recollective judgement expressed by the report of the experience upon retrieval of its representation. Importantly, the occurrence of the first-person pronoun in recollective judgements cannot count as evidence that the mnemonic representation itself involves first-person content.

A further possibility to consider is that the mnemonic representation of putative selfless states might involve first-person content even though the original experience did not. This possibility is consistent with simulation theories of episodic memory, according to which mnemonic representations are (at least partially) constructed during recollection through a process that bears many similarities to imagination (Michaelian, 2016). On such a view, the simulation of the past conscious episode during retrieval might introduce a form of self-representation that was not present in the original experience, simply because it is difficult in the ordinary wakeful state to imagine undergoing a conscious experience lacking selfconsciousness altogether. Furthermore, it has been suggested that the construction of episodic memory involves the enrichment of episodic memory traces with semantic information (Cheng, Werning, \& Suddendorf, 2016). Given the subjects' knowledge that they themselves underwent the recollected episode, it is perhaps not surprising that the mnemonic representation of the episode resulting from semantic enrichment might contain some form of self-representation.

On this interpretation, some reports of totally selfless states that prominently feature the first-person pronoun might be instances of misremembering rather than confabulation, where the main or only inaccuracy is the post-hoc introduction of self-representation within the mnemonic representation. ${ }^{44}$ Importantly, this would not entail that the relevant reports cannot be used to inform research on totally selfless states. Indeed, if the recollection of totally selfless states is systematically biased by structural features of episodic memory construction, then we might be able to abstract away from this systematic bias, and ignore the incongruity of first-person pronoun use in retrospective reports.

In conclusion, it is far from obvious that experiences lacking self-consciousness cannot be remembered as experiences that one has undergone. If such experiences really occur, it is not implausible that they could be reported post hoc. Therefore, we should not dismiss putative reports of such experiences as incoherent or unreliable in principle without further assessment of the accuracy of the recollection process in each individual case.

\section{Conclusion}

Is self-consciousness ubiquitous in conscious experience? To answer this question without engaging in merely verbal disagreements, it is important to disambiguate

\footnotetext{
${ }^{44}$ See Robins (2016) on the difference between remembering, confabulating and misremembering.
} 
different notions of self-consciousness. Starting from the common definition of self-consciousness as consciousness of oneself as oneself, I distinguished six candidate phenomenal features that can qualify as instances of self-consciousness in that sense. I subsequently argued that none of these phenomenal features is necessary for consciousness in general, because there are examples of states of consciousness that credibly lack each of them. Such states of consciousness are at least partially selfless, insofar as they lack at least one of the ways in which one could be conscious of oneself as oneself.

Showing that each of the six putative forms of self-consciousness can be individually missing in conscious experience is not sufficient to rule out all versions of claim that self-consciousness is necessary for consciousness (NC). Indeed, there are a number of disjunctive versions of this claim according to which some form of self-consciousness or other is necessary for consciousness, including the maximally disjunctive claim $\mathbf{N C}_{\text {disj: }}$ :

$\mathbf{N C}_{\text {disj }}$ For any subject $S$, if $S$ is conscious at $t$, then $S$ 's phenomenology involves any of the phenomenal features (1-6) at $t$ (including any combination of these features).

Against all versions of $\mathbf{N C}$ - including $\mathbf{N C}_{\text {disj }}$ - I suggested that some states of consciousness might be totally selfless, insofar as they do not involve any form of self-consciousness. Not only are such states conceptually possible, but they also plausibly occur in some actual conditions. The most promising evidence for the existence of totally selfless states of consciousness arguably comes from reports of certain drug-induced states, although there is also very preliminary evidence that such states may occur during certain forms of meditation practice and during dreamless sleep. Given that a significant part of the relevant evidence remains anecdotal, more empirical research is needed to assess the hypothesis that these states of consciousness really lack all forms of self-consciousness. In particular, reports obtained from questionnaires and semi-structured interviews in controlled conditions could offer more robust evidence regarding the phenomenology of the candidate selfless states. Nonetheless, available evidence speaks to the plausibility of totally selfless states. Furthermore, common objections against the possibility and reportability of such states are misguided.

The upshot of this discussion is twofold. Firstly, proponents of the existence of a sense of self in conscious experience should be explicit about the nature of the target phenomenon. Specifically, they should determine whether the relevant notion of "sense of self" refers to one of the six putative forms of self-consciousness I have distinguished, to a disjunction between several of them and/or their possible combinations, or to an entirely distinct phenomenal feature. Secondly, if their target is indeed one of these six notions or any disjunction between them, they should restrict the scope of their claim to the ordinary experience of healthy, neurotypical adult humans - i.e., to some version of the Typicality Claim (TC) -, because the corresponding versions of the Necessity Claim (NC) are conceptually and empirically implausible. 


\section{Acknowledgments}

I wish to thank the audience of the Selfless Minds workshop in Frankfurt, as well as Dan Zahavi and two anonymous referees for their comments on a previous version of this article. Thanks are also due to Thomas Metzinger, Jennifer Windt and Sascha Fink for their editorial comments. Finally, I am grateful to Martin Davies for comments on previous related materials.

\section{References}

Alcaraz-Sanchez, A. (2019). Conscious states during sleep. A philosophical and psychological exploration (Master's thesis). University of Edinburgh.

Allison-Bolger, V. Y. (1999). Collection of case histories. Unpublished typescript.

Alvarado, C. S. (2000). Out-of-body experiences. In E. Cardeña, S. J. Lynn, \& S. Krippner (Eds.), Varieties of anomalous experiences: Examining the scientific evidence (pp. 183-218). Washington, DC: American Psychological Association.

Anderson, E. W., \& Rawnsley, K. (1954). Clinical studies of lysergic acid diethylamide. European Neurology, 128(1-2), 38-55. https://doi.org/10.1159/000139775

Ataria, Y., Dor-Ziderman, Y., \& Berkovich-Ohana, A. (2015). How does it feel to lack a sense of boundaries? A case study of a long-term mindfulness meditator. Consciousness and Cognition, 37, 133-147. https://doi.org/10.1016/j.concog.2015.09.002

Baird, B., Riedner, B. A., Boly, M., Davidson, R. J., \& Tononi, G. (2019). Increased lucid dream frequency in long-term meditators but not following mindfulness-based stress reduction training. Psychology of Consciousness: Theory, Research, and Practice, 6(1), 40-54. https://doi.org/10.1037/cns0000176

Barsuglia, J., Davis, A. K., Palmer, R., Lancelotta, R., Windham-Herman, A.-M., Peterson, K., et al. (2018). Intensity of mystical experiences occasioned by 5-MeO-DMT and comparison with a prior psilocybin study. Frontiers in Psychology, 9. https://doi.org/10.3389/fpsyg.2018.02459

Bayne, T. (2008). The phenomenology of agency. Philosophy Compass, 3(1), 182-202. https://doi.org/10.1111/j.1747-9991.2007.00122.x

Bayne, T. (2010). The unity of consciousness. Oxford: Oxford University Press.

Bayne, T., \& Spener, M. (2010). Introspective humility. Philosophical Issues, 20(1), 1-22. https://doi.org/10.1111/j.1533-6077.2010.00176.x

Bercel, N. A., Travis, L. E., Olinger, L. B., Dreikurs, E., \& Polos, M. G. (1956). Model psychoses induced by LSD-25 in normals: I. Psychophysiological investigations, with special reference to the mechanism of the paranoid reaction. A.M.A. Archives of Neurology \& Psychiatry, 75(6), 588-611. https://doi.org/10.1001/archneurpsyc.1956.02330240026003

Beringer, K. (1927). Der Meskalinrausch: Seine Geschichte und Erscheinungsweise. Berlin: Springer.

Berkovich-Ohana, A., Dor-Ziderman, Y., Glicksohn, J., \& Goldstein, A. (2013). Alterations in the sense of time, space, and body in the mindfulness-trained brain: A neurophenomenologically-guided MEG study. Frontiers in Psychology, 4. https://doi.org/10.3389/fpsyg.2013.00912

Bermudez, J. L. (1998). The paradox of self-consciousness. Cambridge, MA: MIT Press.

Bermúdez, J. L. (2001). The sources of self-consciousness. Proceedings of the Aristotelian Society, 102(1), 87-107. https://doi.org/10.1111/j.0066-7372.2003.00044.x

Bermúdez, J. L. (2011). Bodily awareness and self-consciousness. In S. Gallagher (Ed.), The Oxford handbook of the self (pp. 157-179). Oxford: Oxford University Press.

Bermúdez, J. L. (2017). Memory and self-consciousness. In K. Michaelian \& Bernecker (Eds.), The Routledge handbook of philosophy of memory (pp. 180-191). London: Routledge.

Bharati, S. V. (2014). My experiments with yoga nidra. Rishikesh, India: Himalayan Yoga Publications Trust.

Billon, A. (2013). Does consciousness entail subjectivity? The puzzle of thought insertion. Philosophical Psychology, 26(2), 291-314. https://doi.org/10.1080/09515089.2011.625117

Billon, A. (2016). Making sense of the Cotard syndrome: Insights from the study of depersonalisation. Mind \& Language, 31(3), 356-391. https://doi.org/10.1111/mila.12110

Billon, A. (2017a). Basic self-awareness. European fournal of Philosophy, 25(3), 732-763. https://doi.org/10.1111/ejop.12168

Billon, A. (2017b). Mineness first: Three challenges to the recent theories of the sense of bodily ownership. In F. de Vignemont \& A. Alsmith (Eds.), The subject's matter: Self-consciousness and the body (pp. 189-216). Cambridge, MA: MIT Press.

Millière, R. (2020). The varieties of selflessness. Philosophy and the Mind Sciences, 1(I), 8. 
Billon, A., \& Kriegel, U. (2015). Jaspers' dilemma: The psychopathological challenge to subjectivity theories of consciousness. In R. J. Gennaro (Ed.), Disturbed consciousness: New essays on psychopathology and theories of consciousness (pp. 29-54). Cambridge, MA: MIT Press.

Blanke, O., \& Metzinger, T. (2009). Full-body illusions and minimal phenomenal selfhood. Trends in Cognitive Sciences, 13(1), 7-13. https://doi.org/10.1016/j.tics.2008.10.003

Block, N. (1995). On a confusion about a function of consciousness. Brain and Behavioral Sciences, 18(2), 227-247. https://doi.org/10.1017/S0140525X00038188

Block, N. (2007). Consciousness, accessibility, and the mesh between psychology and neuroscience. The Behavioral and Brain Sciences, 30(5-6), 481-499; discussion 499-548. https://doi.org/10.1017/S0140525X07002786

Bogzaran, F. (2003). Lucid art and hyperspace lucidity. Dreaming, 13(1), 29-42. https://doi.org/10.1023/A:1022186217703

Bradshaw, M. (2016). A return to self: Depersonalization and how to overcome it. Seattle, WA: Amazon Services International.

Cassam, Q. (1997). Self and world. Oxford: Oxford University Press.

Chadha, M. (2018). No-self and the phenomenology of ownership. Australasian fournal of Philosophy, 96(1), 14-27. https://doi.org/10.1080/00048402.2017.1307236

Chadha, M. (2019). Reconstructing memories, deconstructing the self. Mind \& Language, 34(1), 121-138. https://doi.org/10.1111/mila.12204

Chalmers, D. J. (1996). The conscious mind: In search of a fundamental theory. Oxford: Oxford University Press.

Cheng, S., Werning, M., \& Suddendorf, T. (2016). Dissociating memory traces and scenario construction in mental time travel. Neuroscience \& Biobehavioral Reviews, 60, 82-89. https://doi.org/10.1016/j.neubiorev.2015.11.011

Chisholm, R. M. (1969). On the observability of the self. Philosophy and Phenomenological Research, 30(1), 7-21. https://doi.org/10.2307/2105917

Cicogna, P., \& Bosinelli, M. (2001). Consciousness during dreams. Consciousness and Cognition, 10(1), 26-41. https://doi.org/10.1006/ccog.2000.0471

Conway, M. A. (2005). Memory and the self. fournal of Memory and Language, 53(4), 594-628. https://doi.org/10.1016/j.jml.2005.08.005

Csikszentmihalyi, M. (1990). Flow: The psychology of optimal experience. New York: Harper Collins.

Dainton, B. (2008). The phenomenal self. Oxford: Oxford University Press.

Dainton, B. (2016). The sense of self. Aristotelian Society Supplementary Volume, 90(1), 113-143. https://doi.org/10.1093/arisup/akw007

Damasio, A. (1999). The feeling of what happens: Body and emotion in the making of consciousness. San Diego, CA: Houghton Mifflin Harcourt.

Dammeyer, J. (2014). Deafblindness: A review of the literature. Scandinavian fournal of Public Health, 42(7), 554-562. https://doi.org/10.1177/1403494814544399

D’Argembeau, A. (2018). Mind-wandering and self-referential thought. In K. C. R. Fox \& K. Christoff (Eds.), The Oxford handbook of spontaneous thought (pp. 181-191). Oxford: Oxford University Press.

Davis, A. K., Barsuglia, J. P., Lancelotta, R., Grant, R. M., \& Renn, E. (2018). The epidemiology of 5-methoxy-N,N-dimethyltryptamine (5-MeO-DMT) use: Benefits, consequences, patterns of use, subjective effects, and reasons for consumption. Journal of Psychopharmacology, 32(7), 779-792. https://doi.org/10.1177/0269881118769063

Deane, G. (2020). Dissolving the self: Active inference, psychedelics, and ego-dissolution. Philosophy and the Mind Sciences, 1(I), 2. https://doi.org/10.33735/phimisci.2020.I.39

de Vignemont, F. (2011). Bodily immunity to error. In S. Prosser \& F. Recanati (Eds.), Immunity to error through misidentification: New essays (pp. 1-27). Cambridge: Cambridge University Press.

de Vignemont, F. (2018). Mind the body: An exploration of bodily self-awareness. Oxford: Oxford University Press.

Dor-Ziderman, Y., Berkovich-Ohana, A., Glicksohn, J., \& Goldstein, A. (2013). Mindfulness-induced selflessness: A MEG neurophenomenological study. Frontiers in Human Neuroscience, 7. https://doi.org/10.3389/fnhum.2013.00582

Duncan, M. (2019). The self shows up in experience. Review of Philosophy and Psychology, 10(2), 299-318. https://doi.org/10.1007/s13164-017-0355-2

Dunne, J. (2011). Toward an understanding of non-dual mindfulness. Contemporary Buddhism, 12(1), 71-88. https://doi.org/10.1080/14639947.2011.564820

Evans, G. (1982). The varieties of reference. Oxford: Oxford University Press.

Fazekas, P., Nemeth, G., \& Overgaard, M. (2019). White dreams are made of colours: What studying contentless dreams can teach about the neural basis of dreaming and conscious experiences. Sleep Medicine Reviews, 43, 84-91. https://doi.org/10.1016/j.smrv.2018.10.005

Millière, R. (2020). The varieties of selflessness. Philosophy and the Mind Sciences, 1(I), 8. 
Feinstein, J. S., Khalsa, S. S., Yeh, H. W., Wohlrab, C., Simmons, W. K., Stein, M. B., \& Paulus, M. P. (2018). Examining the short-term anxiolytic and antidepressant effect of floatation-REST. PloS One, 13(2), e0190292-e0190292. https://doi.org/10.1371/journal.pone.0190292

Fink, S. B. (2020). Look who's talking! Varieties of ego-dissolution without paradox. Philosophy and the Mind Sciences, 1(I), 3. https://doi.org/10.33735/phimisci.2020.I.40

Flanagan, O. J. (1992). Consciousness reconsidered. Cambridge, MA: MIT Press.

Fox, K. C. R., \& Cahn, B. R. (forthcoming). Meditation and the brain in health and disease. In M. Farias, D. Brazier, \& M. Lalljee (Eds.), The Oxford handbook of meditation. Oxford: Oxford University Press.

Frege, G. (1956). The thought: A logical inquiry (A. M. Quinton \& M. Quinton, Trans.). Mind, 65(259), 289-311. Retrieved from https://www.jstor.org/stable/2251513 (Original work published 1921)

Friston, K. (2018). Am I self-conscious? ( Or does self-organization entail self-consciousness?). Frontiers in Psychology, 9. https://doi.org/10.3389/fpsyg.2018.00579

Gallagher, S. (2000). Philosophical conceptions of the self: Implications for cognitive science. Trends in Cognitive Sciences, 4(1), 14-21. https://doi.org/10.1016/S1364-6613(99)01417-5

Gallagher, S. (2010). Defining consciousness : The importance of non-reflective self-awareness. Pragmatics and Cognition, 18(3), 561-569.

Gallagher, S., \& Zahavi, D. (2019). Phenomenological approaches to self-consciousness. In E. N. Zalta (Ed.), The stanford encyclopedia of philosophy (Summer 2019). Metaphysics Research Lab, Stanford University.

García-Carpintero, M. (2015). De se thought. https://doi.org/10.1093/oxfordhb/9780199935314.013.61

Guillot, M. (2016). Thinking of oneself as the thinker: The concept of self and the phenomenology of intellection. Philosophical Explorations, 19(2), 138-160. https://doi.org/10.1080/13869795.2016.1176232

Guillot, M. (2017). I me mine: On a confusion concerning the subjective character of experience. Review of Philosophy and Psychology, 8(1), 23-53. https://doi.org/10.1007/s13164-016-0313-4

Gurwitsch, A. (1941). A non-egological conception of consciousness. Philosophy and Phenomenological Research, 1(3), 325-338. https://doi.org/10.2307/2102762

Guttmann, E., \& Maclay, W. S. (1937). Mescaline and depersonalization. fournal of Neurology and Psychopathology, 16(63), $193-212$.

Haggard, P. (2017). Sense of agency in the human brain. Nature Reviews Neuroscience, 18(4), 196-207. https://doi.org/10.1038/nrn.2017.14

Harvey, P. (2012). An introduction to Buddhism: Teachings, history and practices (2nd edition). New York: Cambridge University Press.

Hasenkamp, W. (2018). Catching the wandering mind: Meditation as a window into spontaneous thought. In K. C. R. Fox \& K. Christoff (Eds.), The Oxford Handbook of Spontaneous Thought (pp. 539-553). Oxford: Oxford University Press.

Hobson, J. A. (1988). The dreaming brain (1st edition). New York: Basic Books.

Hoerl, C. (1999). Memory, amnesia and the past. Mind \& Language, 14(2), 227-251. https://doi.org/10.1111/1468-0017.00111

Hohwy, J. (2007). The sense of self in the phenomenology of agency and perception. Psyche, 13(1), 1-20.

Hopkins, G. M. (1959). The sermons and devotional writings of Gerard Manley Hopkins (C. Devlin, Ed.). Oxford: Clarendon Press.

Horgan, T. E., Tienson, J. L., \& Graham, G. (2003). The phenomenology of first-person agency. In S. Walter \& H.-D. Heckmann (Eds.), Physicalism and mental causation (p. 323). Exeter, UK: Imprint Academic.

Howell, R. J. (2006). Self-knowledge and self-reference. Philosophy and Phenomenological Research, 72(1), 44-70. https://doi.org/10.1111/j.1933-1592.2006.tb00490.x

Howell, R. J., \& Thompson, B. (2017). Phenomenally mine: In search of the subjective character of consciousness. Review of Philosophy and Psychology, 8(1), 103-127. https://doi.org/10.1007/s13164-016-0309-0

Hurd, R. (2008). Exploring the void in lucid dreaming. Retrieved from https://dreamstudies.org/2010/05/13/exploring-the-void-in-lucid-dreaming/

Hurley, S. L. (1998). Consciousness in action. Cambridge, MA: Harvard University Press.

Høffding, S., \& Montero, B. G. (2019). Not being there: An analysis of expertise-induced amnesia. Mind \& Language, 1-20. https://doi.org/10.1111/mila.12260

Jackson, S. A., \& Eklund, R. C. (2004). The flow scales manual. Morgantown, WV: Fitness Information Technology.

Jackson, S. A., \& Marsh, H. W. (1996). Development and validation of a scale to measure optimal experience: The flow state scale. Fournal of Sport and Exercise Psychology, 18(1), 17-35. https://doi.org/10.1123/jsep.18.1.17

Janet, P. (1908). Le sentiment de dépersonnalisation. fournal de Psychologie Normale et Pathologique, 5, 514-516.

Millière, R. (2020). The varieties of selflessness. Philosophy and the Mind Sciences, 1(I), 8.

https://doi.org/10.33735/phimisci.2020.I.48

(c) (1) (c) The author(s). https://philosophymindscience.org ISSN: 2699-0369 
Josipovic, Z. (2010). Duality and nonduality in meditation research. Consciousness and Cognition, 19(4), 1119-1121. https://doi.org/10.1016/j.concog.2010.03.016

Josipovic, Z. (2019). Nondual awareness: Consciousness-as-such as non-representational reflexivity. Progress in Brain Research, 244, 273-298. https://doi.org/10.1016/bs.pbr.2018.10.021

Kaplan, D. (1989). Demonstratives. In J. Almog, J. Perry, \& H. Wettstein (Eds.), Themes from Kaplan (pp. 481-563). Oxford: Oxford University Press.

Kjellgren, A., Buhrkall, H., \& Norlander, T. (2010). Psychotherapeutic treatment in combination with relaxation in a flotation tank: Effects on "burn-out syndrome". The Qualitative Report, 15(5), 1243-1269. Retrieved from https://nsuworks.nova.edu/tqr/vol15/iss5/12/

Kjellgren, A., Lyden, F., \& Norlander, T. (2008). Sensory isolation in flotation tanks: Altered states of consciousness and effects on well-being. The Qualitative Report, 13(4), 636-656. Retrieved from https://nsuworks.nova.edu/tqr/vol13/iss4/6

Klatzky, R. (1998). Allocentric and egocentric spatial representations. Spatial Information Theory. A Theoretical Basis for GIS, COSIT93, 716, 14-24.

Klee, G. D. (1963). Lysergic acid diethylamide (LSD-25) and ego functions. Archives of General Psychiatry, 8(5), 461-474. https://doi.org/10.1001/archpsyc.1963.01720110037005

Kriegel, U. (2009). Subjective consciousness: A self-representational theory. Oxford: Oxford University Press.

LaBerge, S., \& DeGracia, D. J. (2000). Varieties of lucid dreaming experience. In R. G. Kunzendorf \& B. Wallace (Eds.), Individual differences in conscious experience (pp. 269-307). Amsterdam, Netherlands: John Benjamins Publishing Company.

Letheby, C. (2020). Being for no-one: Psychedelic experience and minimal subjectivity. Philosophy and the Mind Sciences, 1(I), 5. https://doi.org/10.33735/phimisci.2020.I.47

Letheby, C., \& Gerrans, P. (2017). Self unbound: Ego dissolution in psychedelic experience. Neuroscience of Consciousness, 2017(1), nix016. https://doi.org/10.1093/nc/nix016

Lindahl, J. R., Fisher, N. E., Cooper, D. J., Rosen, R. K., \& Britton, W. B. (2017). The varieties of contemplative experience: A mixed-methods study of meditation-related challenges in Western Buddhists. PLOS ONE, 12(5), e0176239. https://doi.org/10.1371/journal.pone.0176239

Lopez, C., \& Elzière, M. (2018). Out-of-body experience in vestibular disorders A prospective study of 210 patients with dizziness. Cortex, 104, 193-206. https://doi.org/10.1016/j.cortex.2017.05.026

Lou, H. C., Changeux, J. P., \& Rosenstand, A. (2017). Towards a cognitive neuroscience of self-awareness. Neuroscience \& Biobehavioral Reviews, 83, 765-773. https://doi.org/10.1016/j.neubiorev.2016.04.004

Magallon, L. L. (1987). Awake in the dark: Imageless lucid dreaming. Lucidity Letter, 6(1). Retrieved from https://journals.macewan.ca/lucidity/article/download/752/693

Martin, J.-R., \& Pacherie, E. (2013). Out of nowhere: Thought insertion, ownership and context-integration. Consciousness and Cognition, 22(1), 111-122. https://doi.org/10.1016/j.concog.2012.11.012

Martin, M. G. F. (1995). Bodily awareness: A sense of ownership. In J. L. Bermudez, A. J. Marcel, \& N. M. Eilan (Eds.), The body and the self (pp. 267-289). Cambridge, MA: MIT Press.

Masters, R. A. (2005). Darkness shining wild: An odyssey to the heart of hell \& beyond: Meditations on sanity, suffering, spirituality, and liberation. Surrey, BC: Tehmenos Press.

Mayer-Gross, W. (1935). On depersonalization. British fournal of Medical Psychology, 15(2), 103-126. https://doi.org/10.1111/j.2044-8341.1935.tb01140.x

Mayer-Gross, W., \& Stein, H. (1926). Über einige Abänderungen der Sinnestätigkeit im Meskalinrausch. Zeitschrift Für Die Gesamte Neurologie Und Psychiatrie, 101(1), 354-386. https://doi.org/10.1007/BF02878343

McClelland, T. (2019). Against virtual selves. Erkenntnis, 84, 21-40. https://doi.org/10.1007/s10670-017-9945-8

McClelland, T. (forthcoming). Four impediments to the case for mineness. In M. Garcia-Carpintero \& M. Guillot (Eds.), The sense of mineness. Oxford: Oxford University Press.

McGinn, C. (1989). Mental content. Oxford: Basil Blackwell.

Meier, B. (1993). Speech and thinking in dreams. In C. Cavallero \& D. Foulkes (Eds.), Dreaming as cognition (pp. 58-76). Hertfordshire, UK: Harvester Wheatsheaf.

Metzinger, T. (2003). Being no one: The self-model theory of subjectivity. Cambridge, MA: MIT Press.

Metzinger, T. (2013a). The myth of cognitive agency: Subpersonal thinking as a cyclically recurring loss of mental autonomy. Frontiers in Psychology, 4, 931. https://doi.org/10.3389/fpsyg.2013.00931

Metzinger, T. (2013b). Why are dreams interesting for philosophers? The example of minimal phenomenal selfhood, plus an agenda for future research. Frontiers in Psychology, 4, 746. https://doi.org/10.3389/fpsyg.2013.00746

Millière, R. (2020). The varieties of selflessness. Philosophy and the Mind Sciences, 1(I), 8.

https://doi.org/10.33735/phimisci.2020.I.48

(c) () ( T) The author(s). https://philosophymindscience.org ISSN: 2699-0369 
Metzinger, T. (2015). M-autonomy. Journal of Consciousness Studies, 22(11-12), 270-302. Retrieved from https://www.ingentaconnect.com/content/imp/jcs/2015/00000022/F0020011/art00013

Metzinger, T. (2018). Minimal phenomenal experience. MindRxiv. https://doi.org/10.17605/OSF.IO/5WYG7

Metzinger, T. (2020). Minimal phenomenal experience: Meditation, tonic alertness, and the phenomenology of "pure" consciousness. Philosophy and the Mind Sciences, 1(I), 7. https://doi.org/10.33735/phimisci.2020.I.46

Michaelian, K. (2016). Mental time travel: Episodic memory and our knowledge of the personal past. Cambridge, MA: MIT Press.

Millière, R. (2017). Looking for the self: Phenomenology, neurophysiology and philosophical significance of drug-induced ego dissolution. Frontiers in Human Neuroscience, 11(245), 1-22. https://doi.org/10.3389/fnhum.2017.00245

Millière, R. (2019). Are there degrees of self-consciousness? Journal of Consciousness Studies, 26(3-4), 252-276. Retrieved from https:/www.ingentaconnect.com/content/imp/jcs/2019/00000026/f0020003/art00012

Millière, R., Carhart-Harris, R. L., Roseman, L., Trautwein, F.-M., \& Berkovich-Ohana, A. (2018). Psychedelics, meditation and self-consciousness. Frontiers in Psychology, 9(1475), 1-29. https://doi.org/10.3389/fpsyg.2018.01475

Murguialday, A. R., Hill, J., Bensch, M., Martens, S., Halder, S., Nijboer, F., et al. (2011). Transition from the locked in to the completely locked-in state: A physiological analysis. Clinical Neurophysiology, 122(5), 925-933. https://doi.org/10.1016/j.clinph.2010.08.019

Nathan, N. M. L. (1997). Self and will. International fournal of Philosophical Studies, 5(1), 81-94. https://doi.org/10.1080/09672559708570846

Nida-Rümelin, M. (2017). Self-awareness. Review of Philosophy and Psychology, 8(1), 55-82. https://doi.org/10.1007/s13164-016-0328-x

Nielsen, M. (1938). Gerstmann syndrome: Finger agnosia, agraphia, confusion of right and left and acalculia. Comparison of this syndrome with disturbance of body scheme resulting from lesions of the right side of the brain. Archives of Neurology \& Psychiatry, 39(3), 536-560. https://doi.org/10.1001/archneurpsyc.1938.02270030114009

Noë, A. (2005). Action in perception. Cambridge, MA: The MIT Press.

O’Brien, L., \& Soteriou, M. (Eds.). (2009). Mental actions. Oxford: Oxford University Press.

Occhionero, M., \& Cicogna, P. C. (2011). Autoscopic phenomena and one's own body representation in dreams. Consciousness and Cognition, 20(4), 1009-1015. https://doi.org/10.1016/j.concog.2011.01.004

O'Shaughnessy, B. (2000). Consciousness and the world. Oxford: Oxford University Press.

Pahnke, W. N. (1966). Drugs and mysticism: An analysis of the relationship between psychedelic drugs and the mystical consciousness ( $\mathrm{PhD}$ thesis). Harvard University, Cambridge, MA.

Pahnke, W. N., \& Richards, W. A. (1966). Implications of LSD and experimental mysticism. fournal of Religion and Health, 5(3), 175-208. https://doi.org/10.1007/BF01532646

Parker, S. (2017). Yoga nidrā: An opportunity for collaboration to extend the science of sleep states. Sleep and Vigilance, 1(2), 57-63. https://doi.org/10.1007/s41782-017-0026-5

Parker, S. (2019). Training attention for conscious non-REM sleep: The yogic practice of yoga-nidrā and its implications for neuroscience research. In N. Srinivasan (Ed.), Progress in brain research (pp. 255-272). Elsevier.

Parrott, M. (2017). Subjective misidentification and thought insertion. Mind \& Language, 32(1), 39-64. https://doi.org/10.1111/mila.12132

Patel, K. C. (2012). Eastern traditions, consciousness, and spirituality. In L. J. Miller (Ed.), The Oxford handbook of psychology and spirituality (pp. 343-357). Oxford: Oxford University Press.

Peacocke, C. (2006). Mental action and self-awareness. In J. D. Cohen \& B. P. McLaughlin (Eds.), Contemporary debates in the philosophy of mind. Oxford: Blackwell.

Peacocke, C. (2014). The mirror of the world: Subjects, consciousness, and self-consciousness. Oxford: Oxford University Press.

Perry, J. (1979). The problem of the essential indexical. Noûs, 13(1), 3-21. https://doi.org/10.2307/2214792

Pollan, M. (2018). How to change your mind: What the new science of psychedelics teaches us about consciousness, dying, addiction, depression, and transcendence. New York: Penguin Press.

Prinz, J. J. (2012). The conscious brain: How attention engenders experience. Oxford and New York: Oxford University Press.

Proust, J. (2009). Is there a sense of agency for thought? In L. O’Brien \& M. Soteriou (Eds.), Mental actions (pp. 253-279). Oxford: Oxford University Press.

Robins, S. (2017). In defense of Vasubandhu's approach to episodic phenomenology. Australasian Philosophical Review, 1(4), 416-419. https://doi.org/10.1080/24740500.2017.1411148

Robins, S. K. (2016). Misremembering. Philosophical Psychology, 29(3), 432-447. https://doi.org/10.1080/09515089.2015.1113245

Millière, R. (2020). The varieties of selflessness. Philosophy and the Mind Sciences, 1(I), 8. 
Rosenthal, D. M. (1986). Two concepts of consciousness. Philosophical Studies, 49(3), 329-359. https://doi.org/10.1007/BF00355521

Rosenthal, D. M. (1997). A theory of consciousness. In N. Block, O. J. Flanagan, \& G. Guzeldere (Eds.), The nature of consciousness (pp. 729-754). Cambridge, MA: MIT Press.

Rümmele, W., \& Gnirss, F. (1961). Untersuchungen mit Psilocybin, einer psychotropen Substanz aus Psilocybe Mexicana. Schweizer Archiv Für Neurologie, Neurochirurgie Und Psychiatrie, 87, 365-385.

Saks, E. R. (2007). The center cannot hold: My journey through madness. New York: Hachette Books.

Savage, C. (1955). Variations in ego feeling induced by D-lysergic acid diethylamide (LSD-25). Psychoanalytic Review, 42 , 1-16.

Schwenkler, J. (2014). Vision, self-location, and the phenomenology of the "point of view". Noûs, 48(1), 137-155. https://doi.org/10.1111/j.1468-0068.2012.00871.x

Sedman, G., \& Kenna, J. C. (1964). The occurrence of depersonalization phenomena under LSD. European Neurology, 147(3), 129-137. https://doi.org/10.1159/000128893

Seli, P., Ralph, B. C. W., Risko, E. F., W. Schooler, J., Schacter, D. L., \& Smilek, D. (2017). Intentionality and meta-awareness of mind wandering: Are they one and the same, or distinct dimensions? Psychonomic Bulletin \& Review, 24(6), 1808-1818. https://doi.org/10.3758/s13423-017-1249-0

Shankman, R. (2008). The experience of Samadhi: An in-depth exploration of Buddhist meditation. Boston: Shambhala.

Siclari, F., Larocque, J. J., Postle, B. R., \& Tononi, G. (2013). Assessing sleep consciousness within subjects using a serial awakening paradigm. Frontiers in Psychology, 4, 542. https://doi.org/10.3389/fpsyg.2013.00542

Smith, J. (2017). Self-consciousness. In E. N. Zalta (Ed.), The Stanford Encyclopedia of Philosophy (Fall 2017). Metaphysics Research Lab, Stanford University.

Stephens, G. L., Poland, J., \& Radden, J. (2000). When self-consciousness breaks: Alien voices and inserted thoughts. Cambridge, MA: MIT Press.

Strawson, G. (2011). Selves: An essay in revisionary metaphysics. Oxford: Oxford University Press.

Sznycer, D. (2019). Forms and functions of the self-conscious emotions. Trends in Cognitive Sciences, 23(2), $143-157$. https://doi.org/10.1016/j.tics.2018.11.007

Thompson, E. (2015). Dreamless sleep, the embodied mind, and consciousness. In T. K. Metzinger \& J. M. Windt (Eds.), Open MIND. https://doi.org/10.15502/9783958570351

Uthaug, M. V., Lancelotta, R., van Oorsouw, K., Kuypers, K. P. C., Mason, N., Rak, J., et al. (2019). A single inhalation of vapor from dried toad secretion containing 5-methoxy-N,N-dimethyltryptamine (5-MeO-DMT) in a naturalistic setting is related to sustained enhancement of satisfaction with life, mindfulness-related capacities, and a decrement of psychopathological symptoms. Psychopharmacology, 236, 2653-2666. https://doi.org/10.1007/s00213-019-05236-w

Von Mering, O., Morimoto, K., Hyde, R. W., \& Rinkel, M. (1955). Experimentally induced depersonalization. Proceedings of the Annual Meeting of the American Psychopathological Association, 66-77.

Wahbeh, H., Sagher, A., Back, W., Pundhir, P., \& Travis, F. (2018). A systematic review of transcendent states across meditation and contemplative traditions. EXPLORE, 14(1), 19-35. https://doi.org/10.1016/j.explore.2017.07.007

Windt, J. M. (2010). The immersive spatiotemporal hallucination model of dreaming. Phenomenology and the Cognitive Sciences, 9(2), 295-316. https://doi.org/10.1007/s11097-010-9163-1

Windt, J. M. (2015a). Dreaming: A conceptual framework for philosophy of mind and empirical research. Cambridge, MA: MIT Press.

Windt, J. M. (2015b). Just in time-dreamless sleep experience as pure subjective temporality. In T. K. Metzinger \& J. M. Windt (Eds.), Open MIND. Frankfurt am Main: MIND Group.

Windt, J. M. (2017). From Indian philosophy to cognitive neuroscience: Two empirical case studies for Ganeri's self. Philosophical Studies, 174(7), 1721-1733. https://doi.org/10.1007/s11098-016-0826-9

Windt, J. M., Nielsen, T., \& Thompson, E. (2016). Does consciousness disappear in dreamless sleep? Trends in Cognitive Sciences, 20(12), 871-882. https://doi.org/10.1016/j.tics.2016.09.006

Wrigley, W. J., \& Emmerson, S. B. (2011). The experience of the flow state in live music performance. Psychology of Music, 41(3), 292-305. https://doi.org/10.1177/0305735611425903

Zahavi, D. (1999). Self-awareness and alterity: A phenomenological investigation. Evanston, IL: Northwestern University Press.

Zahavi, D. (2005). Subjectivity and selfhood: Investigating the first-person perspective. Cambridge, MA: MIT Press.

Zahavi, D. (2010). Minimal self and narrative self. A distinction in need of refinement. In T. Fuchs, H. C. Sattel, \& P. Henningsen (Eds.), The embodied self: Dimensions, coherence, and disorders (pp. 3-11). Stuttgart: Schattauer.

Zahavi, D. (2014). Self and other: Exploring subjectivity, empathy, and shame. Oxford: Oxford University Press.

Millière, R. (2020). The varieties of selflessness. Philosophy and the Mind Sciences, 1(I), 8.

https://doi.org/10.33735/phimisci.2020.I.48

(c) () ( ) The author(s). https://philosophymindscience.org ISSN: 2699-0369 
Zahavi, D. (2018). Consciousness, self-consciousness, selfhood: A reply to some critics. Review of Philosophy and Psychology, 9(3), 703-718. https://doi.org/10.1007/s13164-018-0403-6

Zahavi, D., \& Kriegel, U. (2016). For-me-ness: What it is and what it is not. In D. O. Dahlstrom, A. Elpidorou, \& W. Hopp (Eds.), Philosophy of Mind and Phenomenology: Conceptual and Empirical Approaches (pp. 36-53). London: Routledge.

\section{Open Access}

This article is distributed under the terms of the Creative Commons Attribution 4.0 International License (https://creativecommons.org/licenses/by/4.0/), which permits unrestricted use, distribution, and reproduction in any medium, as long as you give appropriate credit to the original author(s) and the source, provide a link to the Creative Commons license, and indicate if changes were made. 